\title{
Modulation of Pancreatic Islets' Function and Survival During Aging Involves the Differential Regulation of Endoplasmic Reticulum Stress by p21 and CHOP
}

\author{
Chrysovalantou Mihailidou, Ioulia Chatzistamou, Athanasios G. Papavassiliou, and Hippokratis Kiaris ${ }^{1,3}$
}

\begin{abstract}
Aims: Although endoplasmic reticulum (ER) stress is recognized as a major mechanism causing pancreatic dysfunction in diabetes, little is known on how aging modulates the process. Here, we compared the response with ER stress, viability, and insulin release from pancreatic islets of young (6 weeks) or aged (14 months) mice.

Results: Islets from aged mice were more sensitive to ER stress than their younger counterparts; they exhibited more pronounced unfolded protein response (UPR) and caspase activation and displayed compromised insulin release after high-glucose stimulation. Genetic ablation of p21 sensitized the islets to ER stress, especially in the aged group, whereas $\mathrm{CHOP}$ ablation was protective for islets from both aged and younger animals. Ciclopirox (CPX), an iron chelator that stimulates p21 expression, protected islets from glucotoxicity and mice from dietinduced diabetes, especially in the aged group in a manner that was both p21 and CHOP dependent.

Innovation: For the first time, the study shows that age-dependent susceptibility to diet-induced diabetes is associated with the activity of p21 and CHOP in pancreatic islets and that CPX protects islets from glucotoxicity and mice from diabetes in an age-dependent manner.

Conclusions: Our results identify ER stress as an age-dependent modifier of islet survival and function by mechanisms implicating enhancement of CHOP activity and inhibition of the protective activity of p21. These findings suggest that interventions restoring the homeostatic activity of ER stress, by agents such as CPX, may be particularly beneficial for the management of diabetes in the elderly. Antioxid. Redox Signal. 27, 185-200.
\end{abstract}

Keywords: unfolded protein response, glucotoxicity, glucose, chaperone, beta cells, ciclopirox, aging

\section{Introduction}

A CCUMULATION OF UNFOLDED or misfolded proteins due to various extrinsic or intrinsic factors causes stress of the endoplasmic reticulum (ER) that initially is prosurvival whereas at subsequent stages becomes pro-apoptotic $(10,29$, $33,43)$. The prosurvival activity is attained by elevated chaperone production and translation attenuation, whereas the pro-apoptotic activity is produced by caspase activation $(10,29,33,43)$. Indeed, assessment of the expression levels of various chaperones such as BiP/GRP78 (binding immunoglobulin protein/glucose regulating protein 78) and GRP94 (Glucose Regulated Protein 94) represents a common strat- egy to evaluate whether certain tissues or cells in culture are under ER stress (34).

The pro-apoptotic function of the UPR is especially pertinent to diabetes pathogenesis at which the increased demands for insulin production and secretion, beyond the folding capacity of the pancreatic beta cells, potentiate ER stress and trigger its pro-apoptotic function that ultimately causes pancreatic dysfunction $(1,2,11,12,36,15,25)$. This is related to the progressive reduction of beta cell mass due to ER stress-related apoptosis in the pancreatic islets that results in the reduced production of insulin and characterizes both type I and type II diabetes. Instrumental for ER stressrelated beta cell destruction is the pro-apoptotic transcription

\footnotetext{
${ }^{1}$ Department of Biological Chemistry, National and Kapodistrian University of Athens, Medical School, Athens, Greece.

${ }^{2}$ Department of Pathology, Microbiology and Immunology, University of South Carolina School of Medicine, Columbia, South Carolina.

${ }^{3}$ Department of Drug Discovery and Biomedical Sciences, University of South Carolina, Columbia, South Carolina.
} 


\section{Innovation}

Our study identified the protective activity of the cell cycle regulator p21 and the pro-apoptotic function of the transcription factor $\mathrm{CHOP}$ as age-dependent modifiers of the response of pancreatic islets to glucotoxicity and glucose-induced insulin release, and of the susceptibility of mice to diet-induced diabetes. Further, we show that both in cultured islets in vitro and in mice in vivo, the reactive oxygen species scavenger and iron chelator Ciclopirox effectively protect islets from glucotoxicity and mice from diabetes in a manner that is highly dependent on age.

factor CHOP (CCAAT-enhancer-binding protein homologous protein) that is induced during the UPR and causes apoptosis by mechanisms involving caspase activation $(39,45)$. The significance of CHOP for ER stress-related apoptosis is illustrated by the resistance of the CHOP-deficient mice to diabetes as well as to other ER stress-inducing stimuli, such as the pharmacological inhibition of protein glycosylation, by the antibiotic tunicamycin $(47,48)$. Tunicamycin is an inhibitor of protein glycosylation that is used widely for ER stress induction, because it interferes with protein trafficking and, therefore, causes accumulation of misfolded and unfolded proteins.

Although the molecular queues that govern both the prosurvival and the proapoptotic function of ER stress have been adequately understood, how the transition from the former toward the latter activity is being regulated remains elusive. Elucidation of the shift toward the pro-apoptotic function of the UPR promises application in the management of various ER stress-associated conditions such as diabetes and neurodegeneration. Other and our labs recently demonstrated the pivotal role of $\mathrm{p} 21$ in this process by mechanisms involving inhibition of p21 expression during the advanced stages of ER stress $(23,24,26,28)$. Consistent with these findings, p21 suppression is permissive for the induction of ER stressrelated apoptosis, as it decreases the apoptotic cut-off of cells undergoing ER stress (27). In the context of diabetes, our laboratory demonstrated that genetic ablation of p21 sensitizes mice to diet-induced diabetes whereas its pharmacological stimulation is protective by improving the survival and function of pancreatic islets (23). Mechanistically, the suppression of p21 during ER stress is produced both directly, by mechanisms involving the transcriptional regulation of p21 by CHOP, and indirectly by engaging an alternative form of the p53 tumor suppressor gene that can inhibit p21 expression $(24,28)$.

Aging is recognized as a major modifier of the outcome of ER stress $(30,41)$. Accumulated evidence shows a shift of the unfolded protein response (UPR) toward its pro-apoptotic state during aging, associating ER stress with the onset of aging-associated pathologies, including diabetes $(6,30-32)$. Indeed, many of the components of the UPR exhibit decreased expression and/or activity at advanced ages, which has been related to a compromise of the adaptive function of the UPR (7, 32). Further, it has been shown that at least in Caenorhabditis elegans, an age-dependent misfolding and loss of function of diverse proteins occurs, which indicates a widespread failure in proteostasis at early stages of adulthood, and coincides with a severely reduced activation of the cytoprotective UPR (5). p21 has also been associated with aging, and, indeed, it has been demonstrated that p21 levels gradually decrease in mouse tissues with age, whereas p21 produces anti-aging activity in mice in vivo $(3,37)$.

Taken together, these findings suggest that the differential regulation of the ER stress response in pancreatic islets, by mechanisms that implicate the regulation of $\mathrm{p} 21$ by CHOP, may be associated with the increased prevalence of diabetes at advanced ages (31). Further, it is conceivable that modulation of these activities and enhancement of the adaptive mode of the UPR may be particularly beneficial for the management of age-associated diabetes. To explore these hypotheses, we compared the effects of high-glucoseinduced or tunicamycin-induced ER stress in cultured pancreatic islets from young and aged mice. In view of their ability to regulate the outcome of UPR, in our study, we also included islets from age-matched animals that were deficient for either p21 or CHOP. We also tested the effects of ciclopirox (CPX), a recently discovered activator of p21 (21), on the susceptibility of aged and young mice to diet-induced diabetes, in relation to p21 and CHOP status. This iron chelator was shown to alleviate ER stress and inhibit diabetes in mice, whereas it also protected mammalian neurons from glucotoxicity (20). Our results confirm and extend earlier findings on the significance of p21 and CHOP in the regulation of ER stress and identify aging as a major modifier of UPR by mechanisms, which, at least in part, are related to p21-CHOP deregulation.

\section{Results}

\section{Age and genotype determine the viability of islets} during ER stress

Initially, we explored the effects of age on the viability of pancreatic islets during ER stress. Thus, islets from young (6 weeks old) or aged (14 months old) mice were exposed to high glucose $(25 \mathrm{mM})$ or tunicamycin $(5 \mu \mathrm{g} / \mu \mathrm{l})$ for $24 \mathrm{~h}$, and their viability was assessed. The gross morphology of islets isolated from mice of different genotypes at different ages is shown in Figure 1 (upper panel), respectively. No significant change in the islets' appearance was noted, with the exception that in general islets from older animals were smaller and were isolated with lower efficiency. As shown in Figure 1, both treatments significantly reduced the viability of pancreatic islets isolated from both young and aged mice. However, aged islets exhibited increased sensitivity as compared with their younger counterparts, especially during tunicamycin treatment. Repetition of this experiment with islets isolated from $\mathrm{p} 21$-deficient $(\mathrm{p} 21 \mathrm{KO})$ mice indicated reduced viability of the $\mathrm{p} 21 \mathrm{KO}$ islets during both high glucose and tunicamycin treatment, confirming our earlier findings on the protective role of p21 during ER stress $(23,26)$. Consistent with the proapoptotic role of CHOP during ER stress, genetic ablation of CHOP reduced the cytotoxic effects of ER stress and alleviated the differences between the aged and the young group (Fig. 1).

\section{Caspase activation after ER stress depends on the age of the islets}

In line with the effects on islet survival were the results of caspase activity, under these conditions: As shown in Figure 2, tunicamycin efficiently stimulated caspases $3,6,8$, and 9 activation in wt islets from both young and older 
FIG. 1. Islet viability in culture in relation to the age of the animals. Islets from young (6 weeks old) or aged (14 months old) wt, p $21 \mathrm{KO}$, or CHOPKO mice are shown in the upper panel $(10 \times$ magnification), respectively. Survival of pancreatic islets cultured in the presence of $25 \mathrm{mM}$ glucose or tunicamycin at $5 \mu \mathrm{g} / \mu \mathrm{l}$ for $24 \mathrm{~h}$ is shown in the lower panel. The genotype and the age of the mice from which islets have been isolated are indicated. $* p<0.05 ; * * p<0.005$; $\# p<0.005$ versus controls ( $5.5 \mathrm{~m} M$ glucose). To see this illustration in color, the reader is referred to the web version of this article at www.liebertpub.com/ars
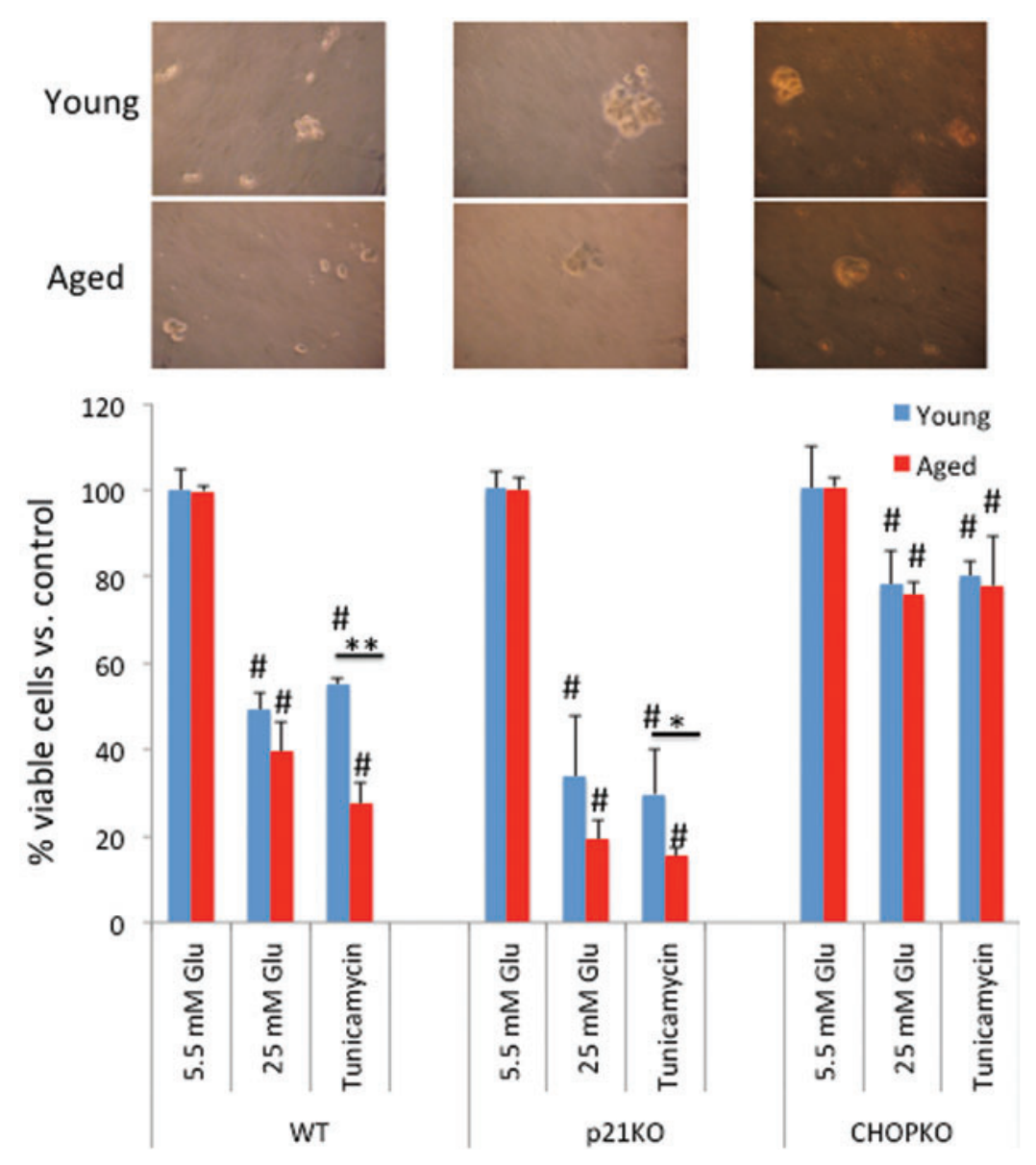

animals. However, culture at high glucose stimulated more than three-fold caspases 3, 6, and 9 activity whereas in islets from younger animals, caspase activity, although significant for caspases 2 and 9, was less than two-fold. Consistent with its pro-apoptotic activity, CHOP ablation reduced caspase activation in both the aged and the young islets. p21 ablation did not compromise caspase activation. For caspase 3 in particular that was unresponsive in the younger islets after $25 \mathrm{~m} M$ glucose treatment, p21 deletion restored its expression. Caspase 3 is recognized as a caspase that is specifically activated during ER stress (14).

\section{CPX protects islets from glucotoxicity and tunicamycin- associated toxicity in a 221 - and CHOP-dependent manner}

CPX is an iron chelator that stimulates p21 expression (21). In view of the sensitizing role of p21 in glucotoxicity, the antidiabetic activity of CPX in mice, and its protective effects against glucotoxicity (20), we tested the effects of CPX on islets' survival in relation to the age of the mice from which the islets had been obtained. As shown in Figure 3, CPX strongly protected islets from death induced by either high glucose or tunicamycin. This effect was recorded in the islets from both young and aged mice, but it was most striking in the latter, increasing islets' survival in the aged group by about $50 \%$. Interestingly, CPX-mediated islets' protection required not only p21 but also intact CHOP activity: Genetic ablation of either p21 or CHOP alleviated the beneficial effects of CPX.
In line with the protective effects of CPX in islets' survival were also the effects of CPX in caspase activity. As shown in Figure 4, CPX significantly reduced the levels of several caspases in the aged group whereas its effects in the younger islets were modest, limited only to caspases 6 and 9 for the islets that were exposed to tunicamycin (Fig. 4). p21 deletion completely abrogated the inhibitory effects of CPX in caspase activity, whereas $\mathrm{CHOP}$ deletion minimized it, restricting to the aged islets and for caspases 3 and 9 in the tunicamycin-treated and in the high-glucose-exposed group, respectively.

\section{Insulin release in pancreatic islets in relation to the age and presence of functional p21 and CHOP}

Subsequently, we explored whether the effects of p21 and CHOP as well as of CPX were limited to islets' survival or also affected their function. To that end, islets were stimulated with $25 \mathrm{mM}$ glucose for $60 \mathrm{~min}$ and the amount of insulin released in the media was assessed by enzyme-linked immunosorbent assay (ELISA). The effects of CPX (20 $\mu M$ Figure 5, baseline levels did not differ considerably between strains. Islets from aged mice released lower baseline levels of insulin as compared with their younger counterparts, which can be due to the progressive, age-dependent compromise of their function as well as due to the reduced beta cell number in the aged islets. This finding, though, was insignificant due to the variation in the insulin levels recorded. Glucose stimulation caused a potent elevation in insulin for $60 \mathrm{~min}$ ) in insulin release were also assessed. As shown in 

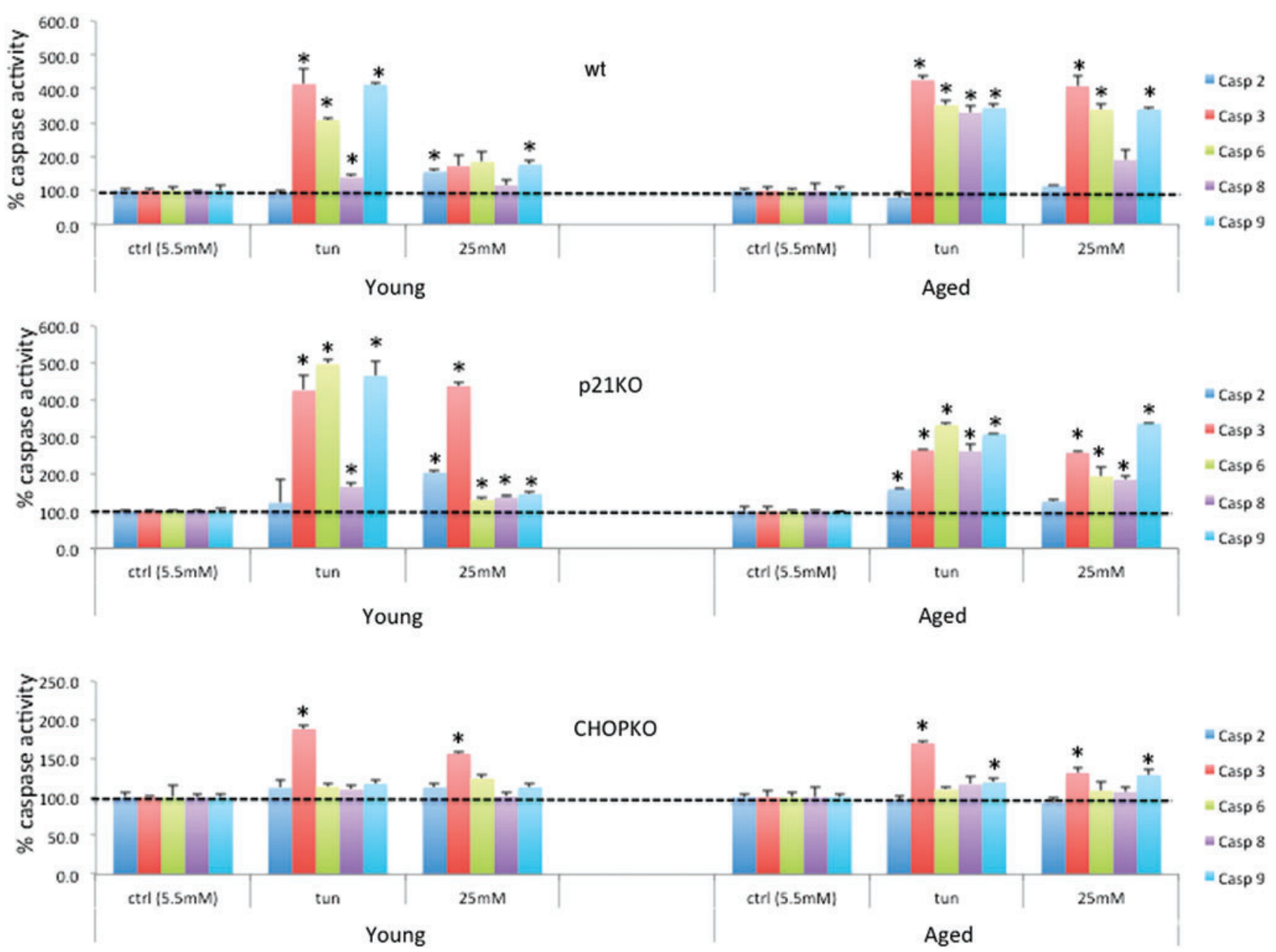

FIG. 2. Caspase activity in cultured islets in culture in relation to the age of the animals. Caspase activity in pancreatic islets from young (6 weeks old) or aged (14 months old) wt, p21KO, or CHOPKO mice, cultured at $5.5 \mathrm{~m} M$ glucose, or $25 \mathrm{mM}$ glucose or tunicamycin $(5 \mu \mathrm{g} / \mu \mathrm{l})$ for $24 \mathrm{~h}$. Results are expressed as $(\%)$ versus age-matched controls. $* p<0.05$. To see this illustration in color, the reader is referred to the web version of this article at www.liebertpub.com/ars

levels released in the media that was partially compromised in the aged wt and $\mathrm{p} 21 \mathrm{KO}$ islets but was still evident and highly significant. In the p21-deficient islets, insulin release was lower than that recorded for the wt islets, suggesting that p21 expression enhances insulin expression (Fig. 5). Noteworthy, CHOP ablation, despite moderately compromised insulin release after glucose stimulation $(525 \%$ vs. $398 \%$ of corresponding controls), strikingly alleviated the age-dependent effects of islets in insulin release, as both islets from young and older CHOPKO mice released similar levels of insulin in the media after glucose stimulation. Then, insulin release was evaluated in the presence of CPX. As shown in Figure 5, the presence of CPX in wt islets, but not in $\mathrm{p} 21 \mathrm{KO}$ or CHOPKO islets, significantly reduced the levels of insulin that were released in the media after glucose stimulation.

\section{Sensitivity of mice to diet-induced diabetes is age dependent and depends on p21 and CHOP}

The strong role of age in the effects of glucotoxicity and function of pancreatic islets in vitro implies that sensitivity to diet-induced diabetes is age dependent and will also depend highly on p21 and CHOP expression. To test this hypothesis, we generated cohorts of young (6 weeks) and aged (14 months old) wt, p21KO, and CHOPKO mice, subjected them to a sucrose-high-fat diet (HFDSUC) (15), and monitored disease onset by biweekly measurements of glucose in the mice plasma. This diet induces a prediabetic condition that is characterized by progressively increasing levels of blood glucose (23). We reasoned that the fact that full-blown diabetes is not induced would allow more accurate and clinically relevant simulation of aging-associated diabetes. As expected, aged wt animals were more sensitive to diabetes development than their younger counterparts (Fig. 6). For the animals in which p21 had been deleted, diabetes progressed more rapidly than in wt animals, for both the young and the aged group, exhibiting statistically significant elevated glucose levels as early as 3 days after HFDSUC administration being $105.2 \pm 5.7 \mathrm{mg} / \mathrm{dl}$ versus $116.2 \pm 5.2 \mathrm{mg} / \mathrm{dl}$ for the young $\mathrm{wt}$ and the p21KO animals, respectively $(p<0.05)$ (Fig. 6). For the older animals on day 3 after HFDSUC administration, glucose levels were $115 \pm 3.5 \mathrm{mg} / \mathrm{dl}$ versus $129 \pm 3.3 \mathrm{mg} / \mathrm{dl}(p<0.05)$. CHOPKO mice were more resistant to diabetes development than both wt and p21KO mice, and the effect of aging was practically abolished as both young and aged mice exhibited an overlapping profile for diabetes development. 

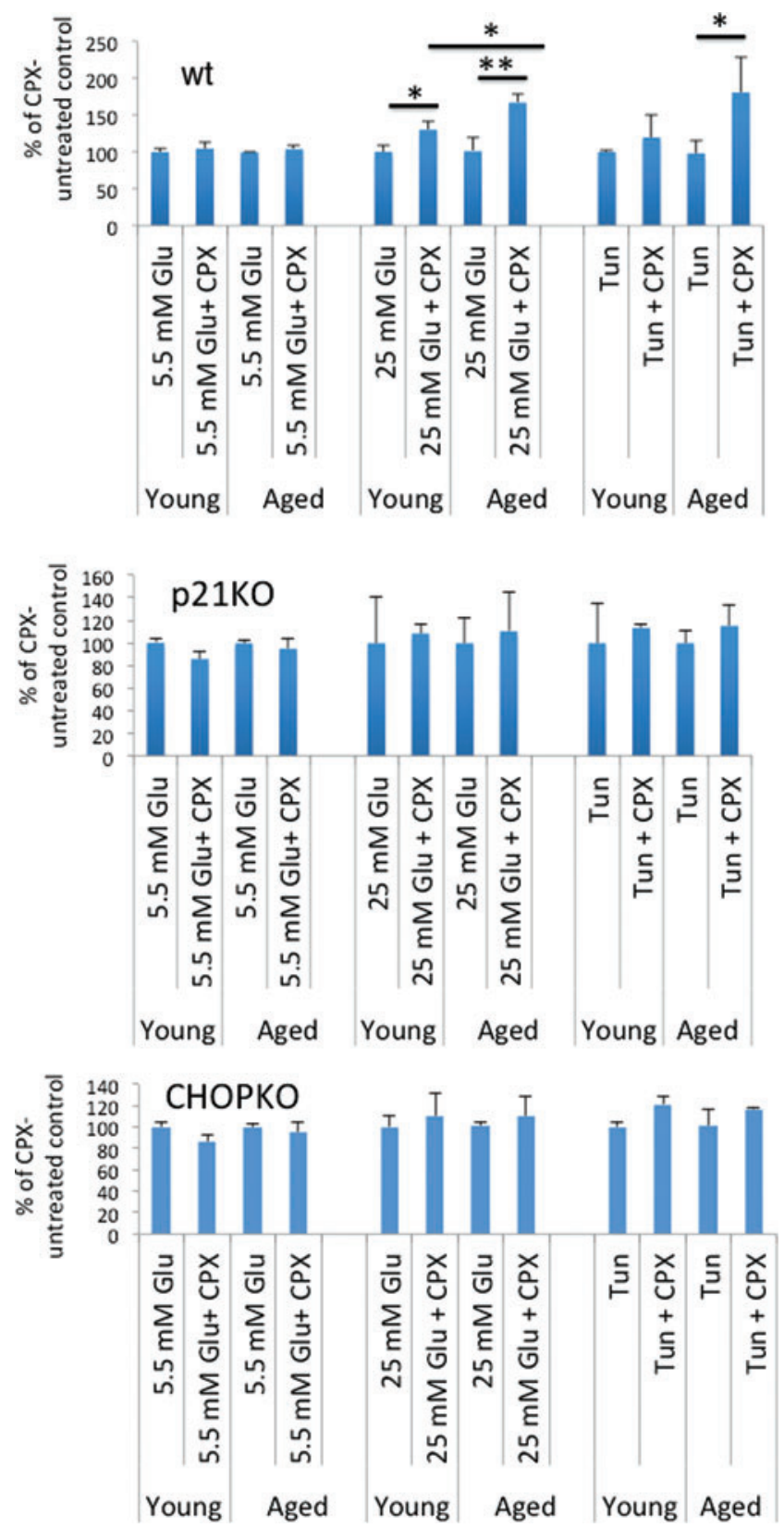

FIG. 3. CPX alleviates the cytotoxicity of high glucose and tunicamycin in islets from young and aged animals. Islets' survival cultured in conditions of normal glucose $(5.5 \mathrm{~m} M)$ or high glucose $(25 \mathrm{mM})$ or tunicamycin $(5 \mu \mathrm{g} / \mu \mathrm{l})$ for $24 \mathrm{~h}$, respectively, or in combination with CPX at $20 \mu M$ for $24 \mathrm{~h}$. Islets' genotype is indicated in the top left of each graph. Results are expressed as \% of CPX-untreated control cultured at the same glucose concentrations or tunicamycin (as opposed to regular $5.5 \mathrm{~m} M$ glucose), but without $\mathrm{CPX}$ and thus, in the presence of CPX survival may exceed $100 \%$ to underscore the CPX-contributed protection. ${ }^{*} p<0.05$; ${ }^{*} p<<0.005$. CPX, Ciclopirox. To see this illustration in color, the reader is referred to the web version of this article at www.liebertpub.com/ars

\section{CPX protects mice from diet-induced diabetes by a mechanism that is $p 21$ and CHOP dependent and is more potent during aging}

In view of the protective effect of CPX on islet viability and function, we investigated whether pretreatment of mice with CPX protects from diabetes development. We also explored whether for these effects, intact p21 and CHOP activity was required. Thus, cohorts of mice, as described earlier, before subjection in sucrose/HFD received tri-weekly CPX by oral gavages for 1 month. As shown in Figure 6, left panel pretreatment of mice with CPX protected both the younger and the older animals from diabetes. This effect was more potent for the aged mice, since both young and aged mice reached similar levels of circulating glucose after CPX administration, despite that in the saline-treated group the aged mice became diabetic faster. In the p21KO-treated group, though, despite that aging accelerated diabetes development, CPX was ineffective. Thus, CPX requires intact p21 activity to protect from diet-induced diabetes. Similar were the results recorded for the CHOPKO mice (Fig. 6 left panel).

\section{Age-dependent induction of ER stress by tunicamycin and high glucose}

To better understand the age-dependent role of p21 and $\mathrm{CHOP}$ in islets cultured at high glucose and tunicamycin, we assessed the induction of UPR in relation to the age of the mice from which the islets had been isolated. As shown in Figure 7 (upper panel) and Supplementary Figure S1 (Supplementary Data are available online at www.liebertpub .com/ars), as reflected in the protein levels of BiP, GRP94, and CHOP, UPR was triggered in both the young and the wild-type aged islets, with the latter exhibiting a more pronounced response that is in line with their increased sensitivity to the cytotoxic effects of ER stress described in Figure 1. Interestingly, the baseline levels of these ER stress markers were reduced in the aged group, suggesting that it is the inducibility rather than the absolute levels at the relaxed (unstressed) conditions that are associated with the outcome of the ER stress response. Under these conditions, p21 expression was suppressed and this inhibitory effect was more potent in the islets from the aged group. Similar effects on p21 expression were obtained in cultured pancreatic islets from rats that had been exposed to increasing concentrations of glucose and then subjected to microarray analyses (Supplementary Fig. S2) (4). Deletion of p21, and despite its potent effects in islet survival and function, only minimally affected the expression (and the induction) of BiP, GRP94, and CHOP in both the young and the aged islets (Fig. 7, medium panel and Supplementary Fig. S1). CHOP ablation, however suppressed both their baseline expression and their expression after ER stress in both the young and the aged group (Fig. 7 lower panel and Supplementary Fig. S1). As regards $\mathrm{p} 21$, despite that baseline levels were reduced in the absence of ER stress, CHOP ablation during tunicamycin and high-glucose treatment reverted the $\mathrm{p} 21$ suppression seen in wt islets to a moderate induction (Fig. 7, lower panel and Supplementary Fig. S1).

\section{Plasma insulin in p21 and CHOP-deficient animals in relation to age, diet, and CPX administration}

Subsequently, we assessed insulin levels in the plasma of wt, p21KO, and $\mathrm{CHOPKO}$ mice subjected to a regular diet or SUCHFD (1 month), in the presence or absence of CPX. In this experiment, CPX was administered before SUCHFD for about 1 month. As shown in Figure 6a (right panel), the profile of insulin in the plasma followed, in general, the 

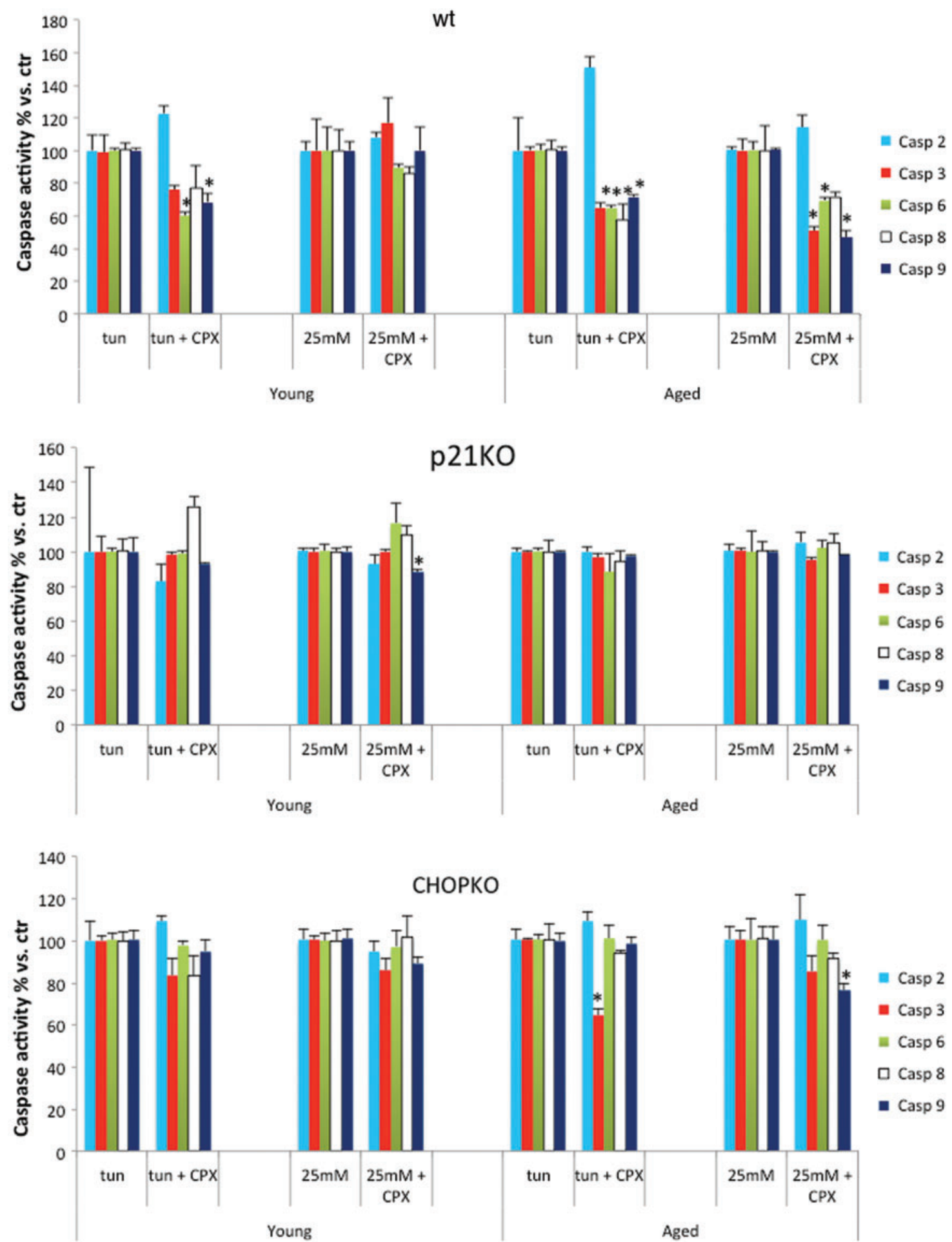

FIG. 4. CPX reduces the levels of caspase activity. Caspase activity in pancreatic islets from young (6 weeks old) or aged (14 months old) wt, p21KO, or CHOPKO mice, cultured at $25 \mathrm{~m} M$ glucose or tunicamycin $(5 \mu \mathrm{g} / \mu \mathrm{l})$ for $24 \mathrm{~h}$ in the presence or absence of CPX. Results are expressed as\% versus age-matched controls that had not been treated with CPX. ${ }^{*} p<0.05$. To see this illustration in color, the reader is referred to the web version of this article at www.liebertpub.com/ars

profile of insulin release in cultured islets (Fig. 5a) and that of plasma glucose in vivo (Fig. 6a, left panel). As expected, HFDSUC caused an elevation in fasting insulin levels, which was compromised in the aged wt, but not the CHOPKO and p $21 \mathrm{KO}$ animals, which exhibited similar insulin levels in the two age cohorts examined. In wt animals that had received CPX, insulin levels were lower. In CHOPKO animals, this CPX-associated reduction was also detectable but more modest; whereas in the p21KO animals, it was seen only in the aged but not in the younger animals. Assessment of 


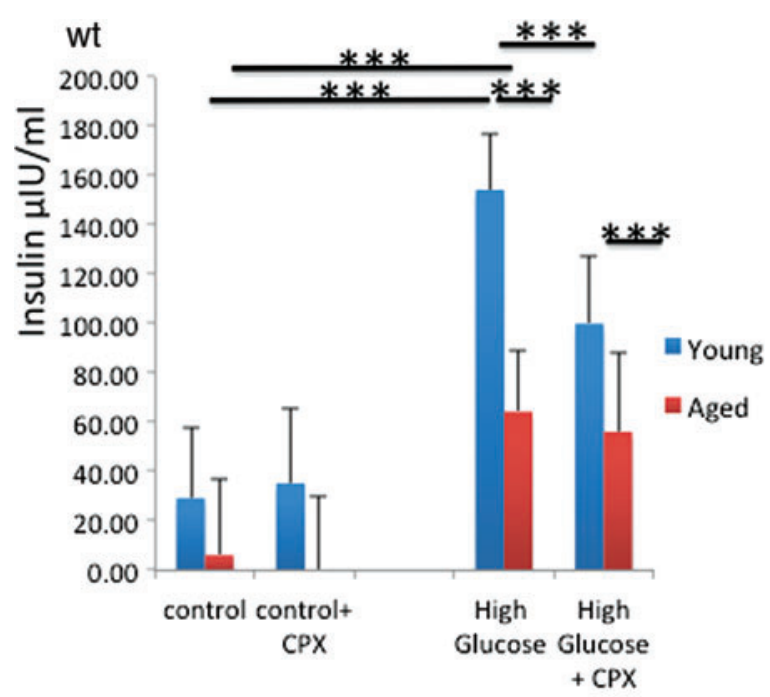

glucose $30 \mathrm{~min}$ after administration of $0.75 \mathrm{U}$ insulin $/ \mathrm{kg}$ body in wt animals showed that insulin sensitivity was increased in the CPX-receiving animals (Fig. 6b).

\section{CPX suppresses UPR in a p21-dependent manner}

As shown in Figure 7 in wt islets, CPX for $24 \mathrm{~h}$ stimulated p21 expression in the aged group and prevented high glucose or tunicamycin-induced p21 suppression in the islets of both younger and particularly aged animals. These effects were even more prominent after $6 \mathrm{~h}$ treatment, implying the operation of compensatory mechanisms (Supplementary Fig. S3). All three ER stress-associated markers tested showed some reduction after CPX treatment, but inducibility after either tunicamycin or high-glucose culture was retained, notwithstanding the fact that stimulation was reduced. During both p21 and CHOP deletion though, their induction was compromised after application of the ER stress-inducing stimuli, suggesting that both $\mathrm{p} 21$ and $\mathrm{CHOP}$ are required for the development of the UPR (Fig. 7 and Supplementary Fig. S1).
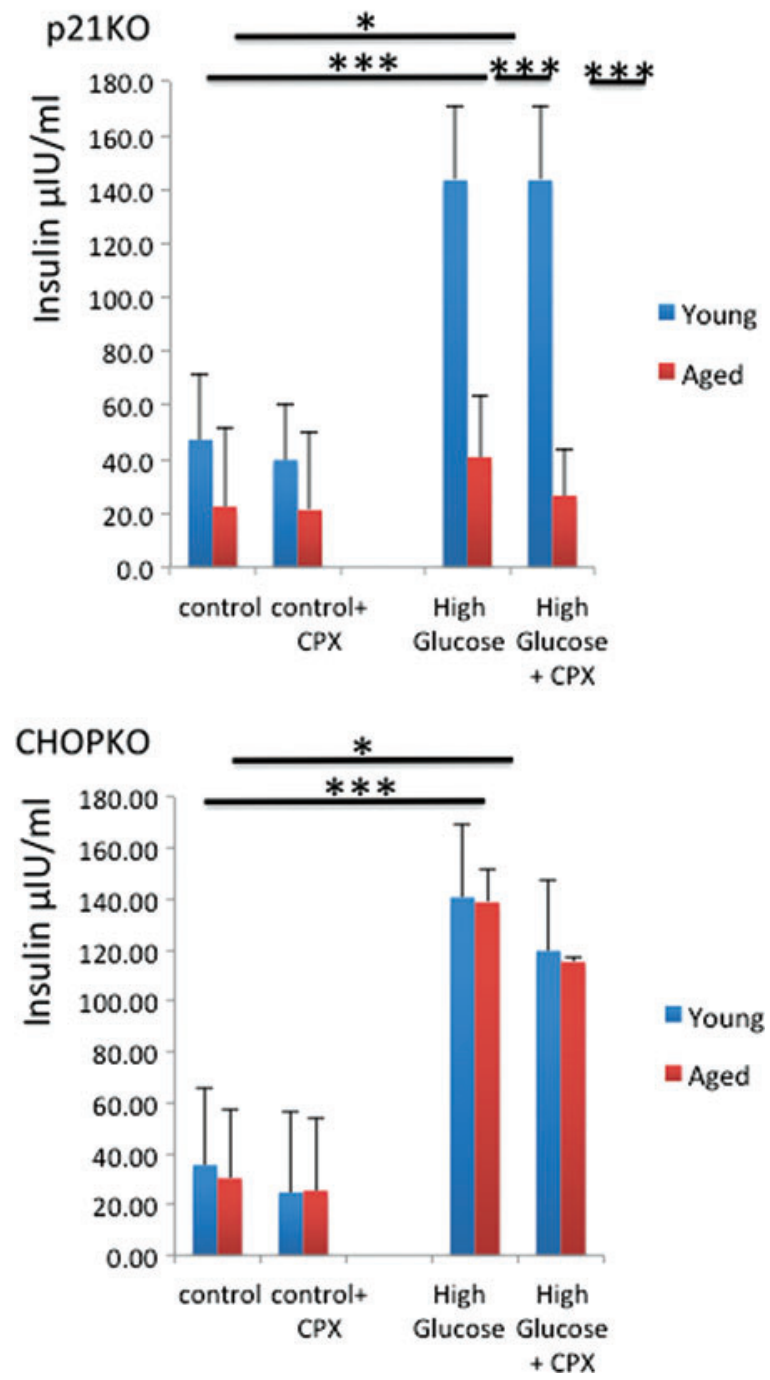

FIG. 5. Glucose-stimulated insulin secretion decreased with age. Insulin levels released in the media of islets from young (6 weeks old) or aged (14 months old) wt, p21KO, or CHOPKO mice, stimulated with $25 \mathrm{mM}$ glucose for $60 \mathrm{~min}$. The effects of $\mathrm{CPX}$ at $20 \mu \mathrm{M}$ for $60 \mathrm{~min}$ in insulin release are shown. ${ }^{*} p<0.05$; $* * * p<0.001$. To see this illustration in color, the reader is referred to the web version of this article at www.liebertpub.com/ars

\section{The effects of CPX in p21 and CHOP expression are dose dependent}

The ER stress-inhibiting activity of CPX contradicts the recently reported stimulation of CHOP expression by deferoxamine (DFO), another commonly used iron chelator (16). To explore this in more detail, islets from 6-week-old mice were exposed to increasing concentrations of CPX and DFO and p21 and CHOP levels were assessed. As shown in Figure 8, CPX caused a dose-dependent induction in p21 expression whereas $\mathrm{CHOP}$ expression was inhibited at higher doses after stimulation after exposure at lower doses of CPX. However, DFO, at higher doses, stimulated CHOP expression and suppressed the expression of p21 (Fig. 8 and Supplementary Fig. S4).

\section{Age-dependent binding of CHOP at the p21 promoter}

We have recently shown that at least partly, p21 is regulated by $\mathrm{CHOP}$ at the level of transcription by a mechanism involving the binding of CHOP to the promoter of $\mathrm{p} 21$ (23, 24). To test whether differential binding occurs in the promoter of $\mathrm{p} 21$ by CHOP, we performed chromatin immunoprecipitation (ChIP) studies in islets from young and aged mice after induction of ER stress by tunicamycin and high glucose. As shown in Figure 9a, both tunicamycin and high glucose increased the occupancy of p21 by CHOP. Importantly, this effect was slightly more prominent in the islets from the older mice, which is in line with the increased sensitivity of the aged mice and islets to ER stress-inducing stimuli. In the presence of CPX, binding was moderately reduced. In line with these findings were also the results of a semiquantitative qPCR analysis that showed that during stress by high glucose or tunicamycin, p21 RNA levels decreased in wt, but not in CHOPKO islets and that this effect was potentiated in islets from older mice (Fig. 9b).

\section{Regulation of reactive oxygen species production by $p 21$ and CHOP in the presence of CPX}

In view of the ability of CPX to scavenge reactive oxygen species (ROS) (41) and the ability of antioxidants to reduce 

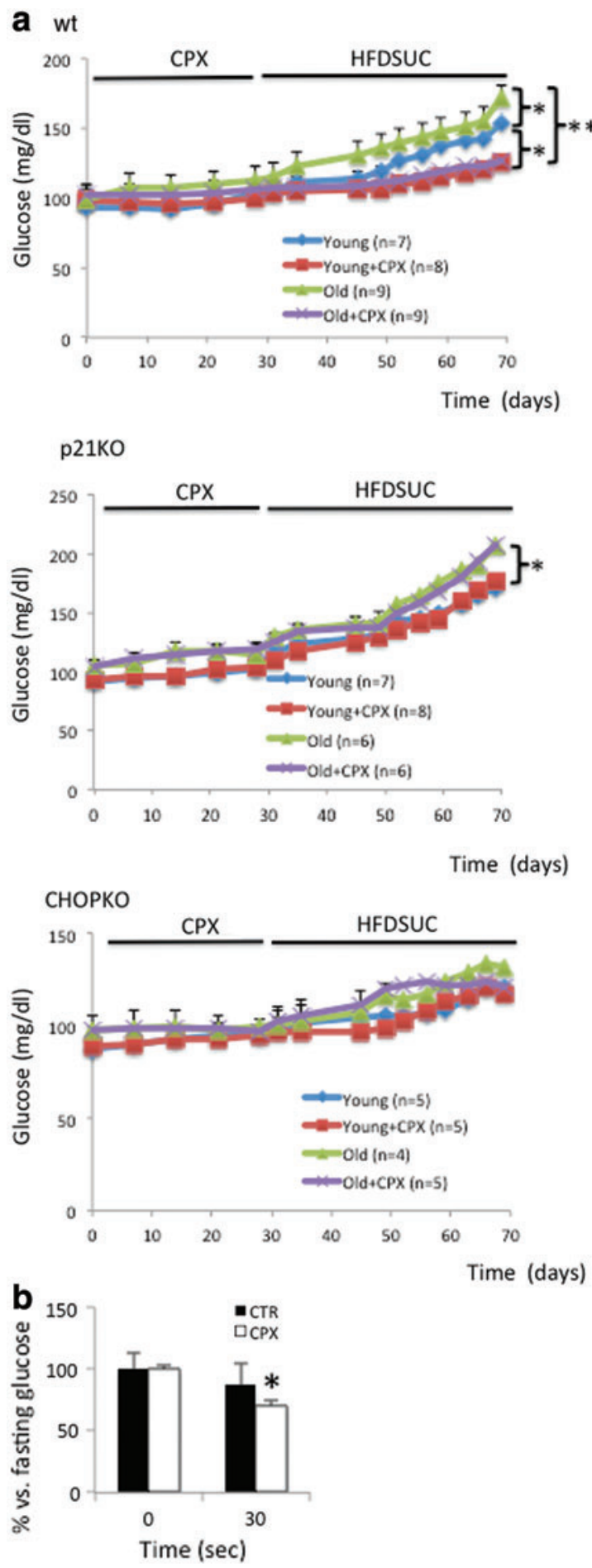
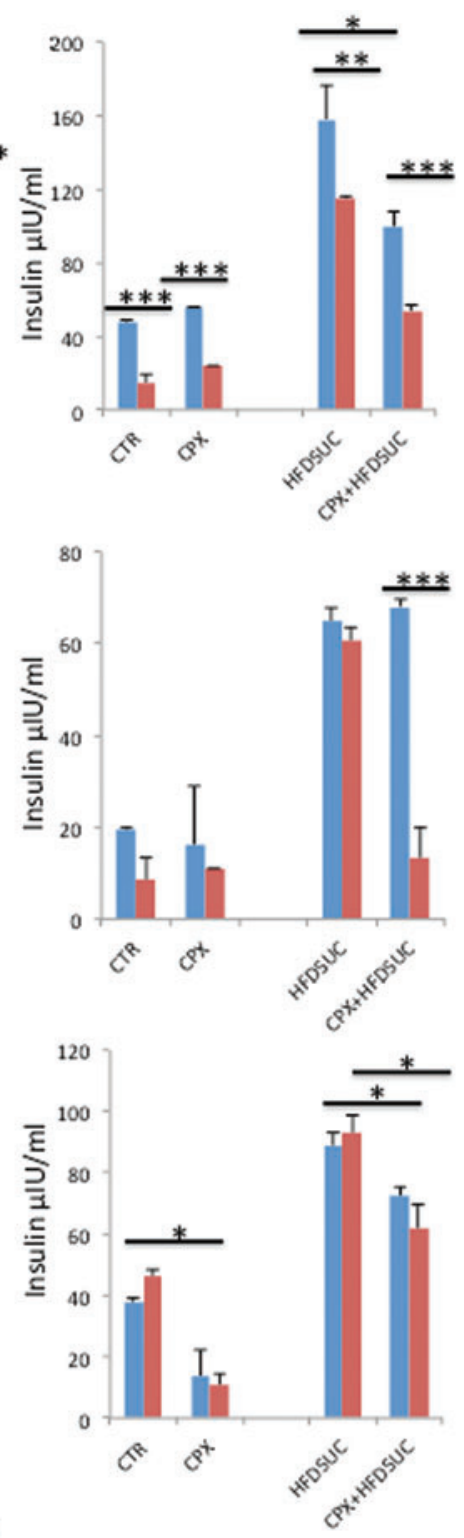

FIG. 6. Aging correlates with enhanced sensitivity to diabetes development, whereas CPX promotes the recovery from HFDSUC injury. (a) (Left panel) Circulating glucose levels in wt, p21KO, or CHOPKO from young ( 6 weeks old) or aged (14 months old) mice that have been pretreated with CPX or vehicle control and, subsequently, received sucrose/ high-fat diet (HFDSUC). The number (n) of mice with the indicated ages and genotypes used is shown within each graph. Fasting insulin levels $(\mu \mathrm{IU} / \mathrm{ml})$ in 6 week-old or 9 month-old mice that have received CPX after HFDSUC as described (right panel) $(n=2)$. (b) Glucose after administration of $0.75 \mathrm{U}$ insulin $/ \mathrm{kg}$ body in wt animals that have received CPX and HFDSUC $(n=6) . * p<0.05 ; * * p<$ 0.005 ; *** $p<0.001$. To see this illustration in color, the reader is referred to the web version of this article at www.liebertpub.com/ars
ER stress (22), we evaluate in animals from 6 week- and 11 month-old mice ROS production cultured at elevated glucose concentrations. Measurements were performed by both DCFDA (Fig. 10a)- and 8-OHdG (Fig. 10b)-based assays, which gave similar results. As shown in Figure 10, increasing glucose concentrations stimulated the production of ROS in wt islets, an effect that was more profound in the islets from the older animals. CPX significantly $(p<0.05)$ suppressed ROS production in the younger but not in the older islets. Genetic ablation of p21 did not affect ROS production, but it alleviated this protective effect of CPX. CHOP deletion strongly suppressed ROS production triggered by high glucose in both young and older islets and minimized the protective effect of CPX, which was significant, although minimal, only in the younger islets.

To test whether the results of ROS measurements in cultured islets were in line with the in vivo results, we evaluated the levels of 8-hydroxy-2' -deoxyguanosine (8-OHdG) in the liver and pancreas of wt, CHOPKO, and $\mathrm{p} 21 \mathrm{KO}$ mice that have been subjected to HFDSUC alone or in combination 

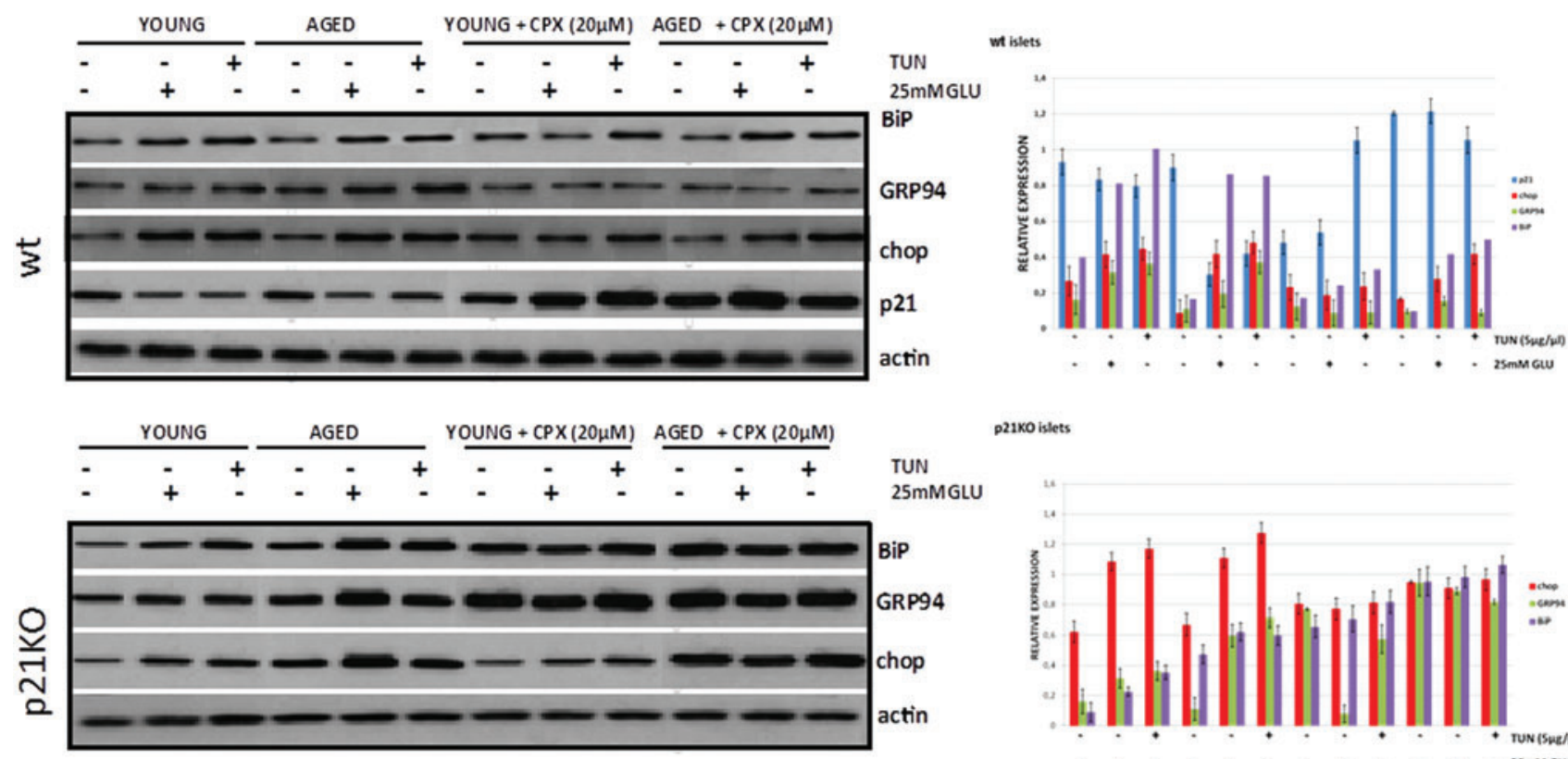

p21ko islets
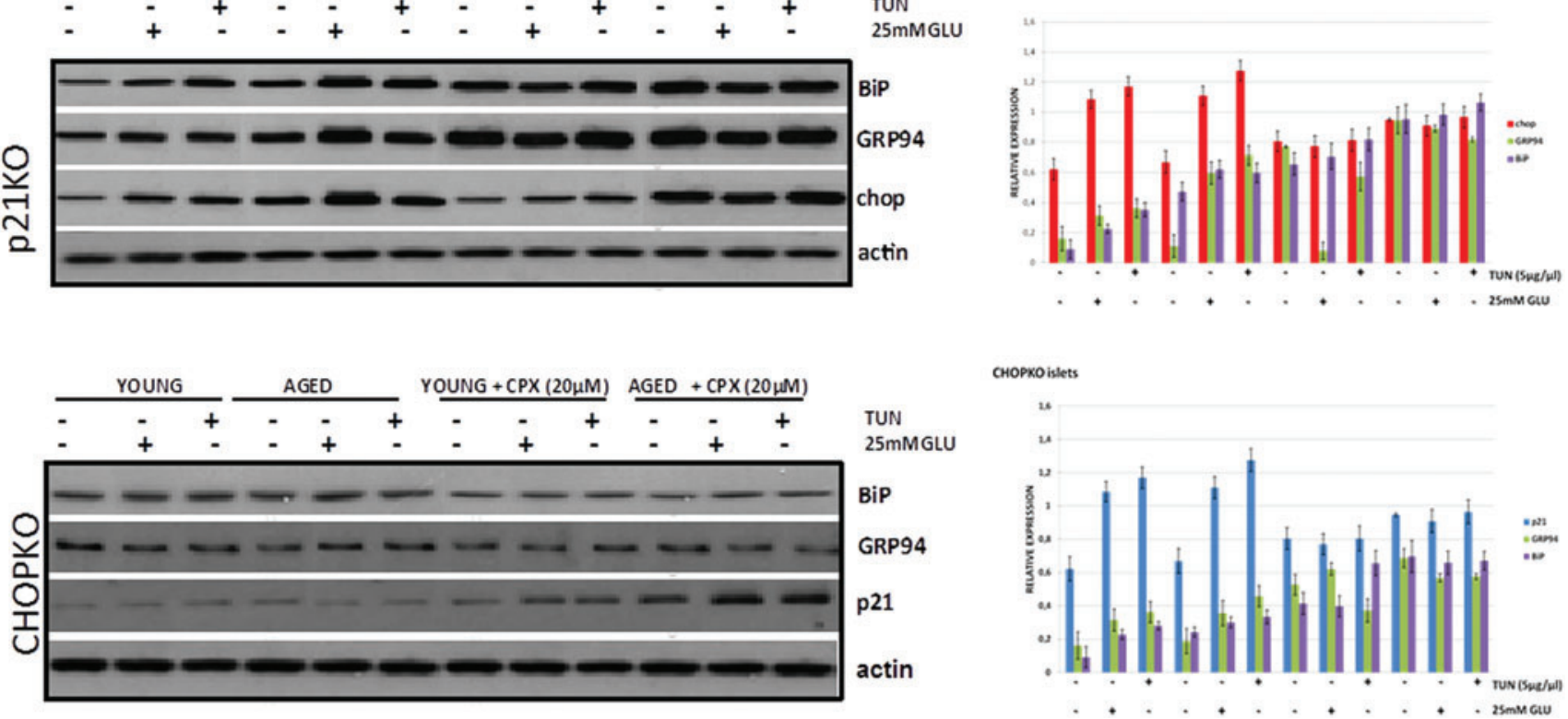

FIG. 7. Age elevates ER stress markers, whereas CPX re-establishes ER-stress homeostasis. Expression of chaperones GRP94 and BiP/GRP78, of transcription factor $\mathrm{CHOP}$ and of cell cycle regulator p21 in cultured pancreatic islets isolated from wild-type, p21KO, or CHOPKO, young (6 weeks old) or aged (14 months old) mice, after exposure to normal glucose (CTRL, $5.5 \mathrm{mM})$ or high glucose $(25 \mathrm{mM})$ or tunicamycin $(5 \mu \mathrm{g} / \mu \mathrm{l})$ (Left panel) $(n=3$ per experimental group). The effects of concomitant exposure of islets to CPX $(20 \mu M$ for $24 \mathrm{~h})$ were also assessed. Actin levels were assessed as a loading control. Quantification of each blot is shown in the right panel and reflects average values \pm SEM of two biological replica experiments. ER, endoplasmic reticulum. To see this illustration in color, the reader is referred to the web version of this article at www .liebertpub.com/ars
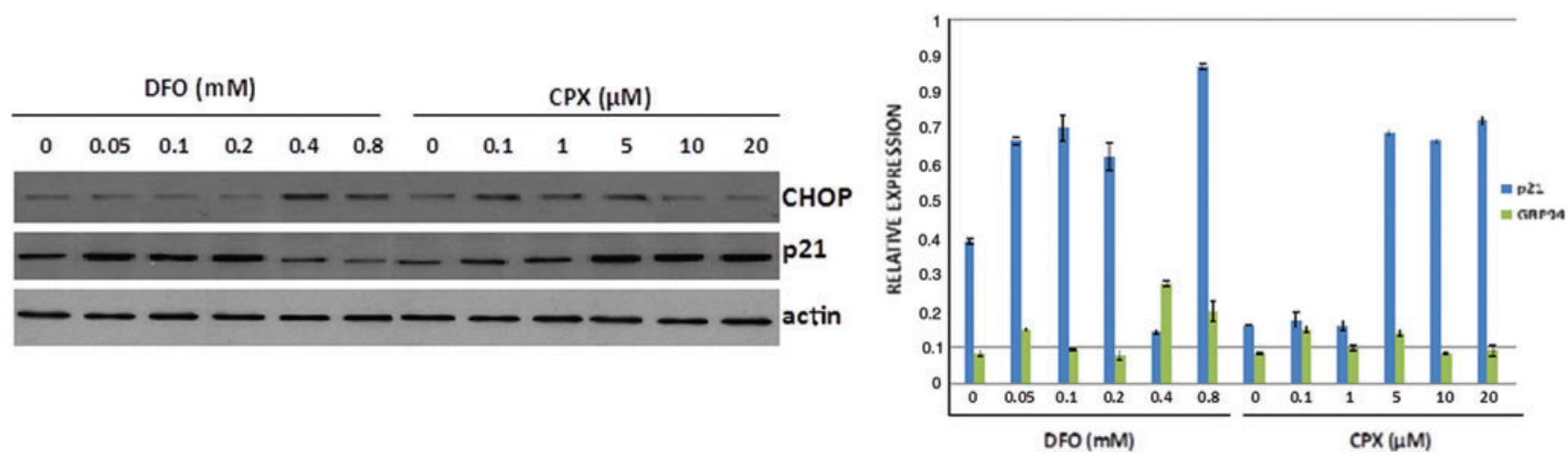

FIG. 8. Effects of CPX and DFO in p21 and CHOP expression. The expression of increasing amounts of CPX or DFO for $24 \mathrm{~h}$ in $\mathrm{p} 21$ and CHOP expression in cultured islets is shown in the left panel ( $n=3$ per experimental group). Actin levels were assessed as a loading control. Quantification of each blot is shown in the right panel and reflects average values \pm SEM of two biological replica experiments. DFO, deferoxamine. To see this illustration in color, the reader is referred to the web version of this article at www.liebertpub.com/ars 
a
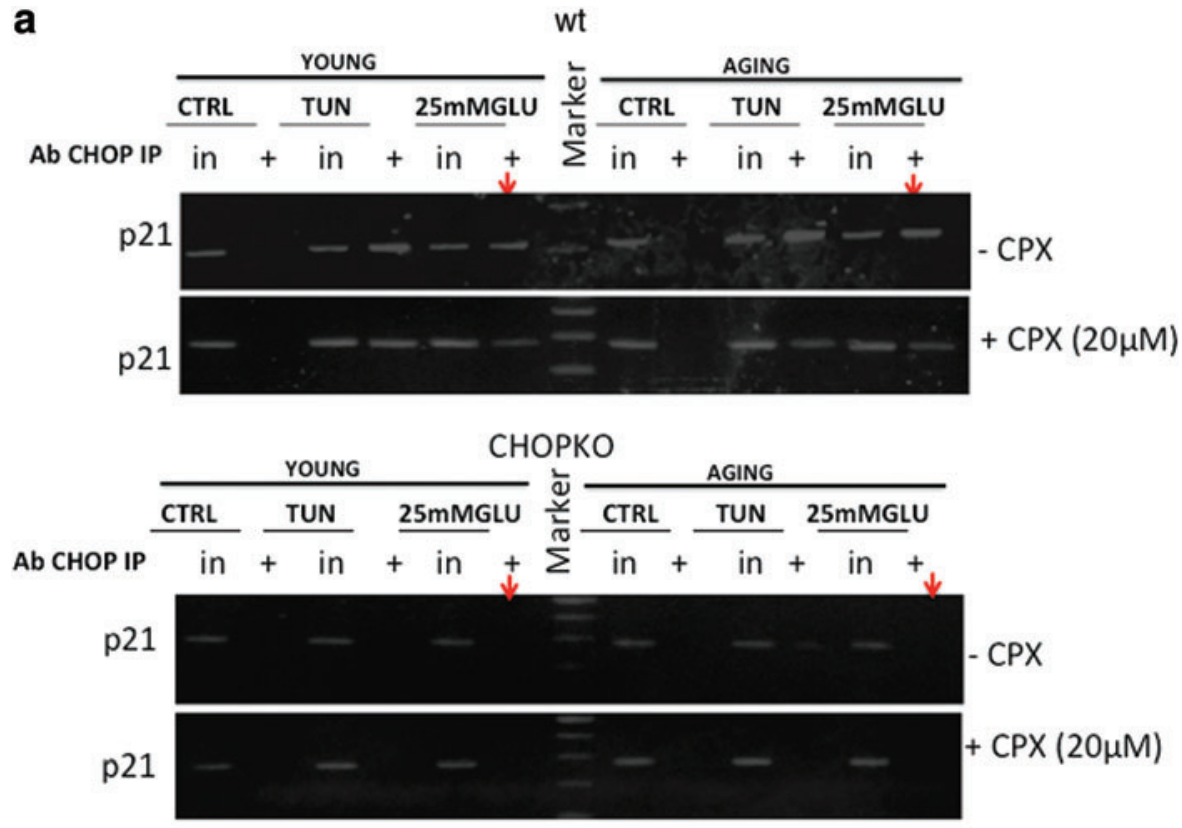

b

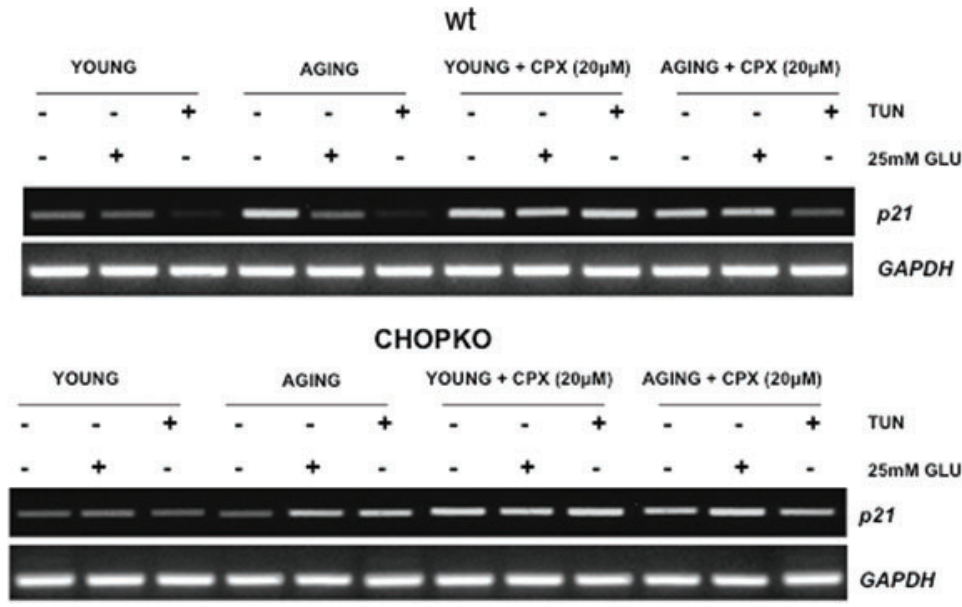

FIG. 9. Age correlates with enhanced binding of CHOP at the p21 promoter. (a) ChIP for $\mathrm{CHOP}$ in p21 promoter in pancreatic islets from young (6 weeks old) or aged (14 months old) mice, after exposure to high glucose $(25 \mathrm{mM})$ or tunicamycin $(5 \mu \mathrm{g} / \mu \mathrm{l})$. The experiment was repeated in the presence of CPX at $20 \mu M$ for $24 \mathrm{~h}$. The red arrows point to the binding of $\mathrm{CHOP}$ to the p21 promoter in islets from young and aged mice at $25 \mathrm{mM}$ glucose. (b). RT-PCR analysis for $p 21$ expression under the conditions described in (a). GAPDH expression was used as a control for RNA quality. ChIP, chromatin immunoprecipitation. To see this illustration in color, the reader is referred to the web version of this article at www.liebert pub.com/ars with CPX. 8-OHdG is considered an accurate marker of oxidative stress in vivo (44). As shown in Figure 11, HFDSUC diet induced 8-OHdG levels in the liver and pancreas of both older and younger wt mice, with the induction in the former surpassing that of the latter, which also showed increased baseline levels even in the controls. CPX treatment reduced the induction by a p21-dependent mechanism, since in $\mathrm{p} 21 \mathrm{KO}$ mice CPX was ineffective. In CHOPKO mice, HFDSUC caused a moderate stimulation in the pancreas of the older mice only; whereas in the liver, both younger and older mice exhibited elevated levels of $8-\mathrm{OHdG}$ in the HFDSUC group and increased baseline levels in the older mice (Fig. 11).

\section{Discussion}

In the present study, we explored the role of aging in the sensitivity of mice to diet-induced diabetes and in the function and survival of pancreatic islets to the ER stressinducing stimuli tunicamycin and high glucose. The role of p21 and CHOP, which regulates the outcome of UPR, was also evaluated by utilizing $\mathrm{p} 21$ - and $\mathrm{CHOP}$-deficient pancreatic islets and animals. Finally, we assessed whether CPX, an iron chelator that stimulates the expression of $\mathrm{p} 21$, protects from diabetes. Our results show that at an advanced age, islets become more sensitive to ER stress-inducing stimuli and that this effect is CHOP dependent: Genetic ablation of CHOP was sufficient, not only to confer resistance to the cytotoxic effects of UPR and to diabetes in mice, which is consistent with its proapoptotic role (35), but also to abrogate the effects of aging in the sensitivity to ER stress. To that end, modulation of CHOP activity emerges as a major regulator of the age-dependent effects of UPR and an important determinant of the increased sensitivity of the elderly to diabetes.

In line with our previous observations (23), p21 ablation sensitized islets to ER stress and mice to diet-induced diabetes, confirming its protective role in the cytotoxic effects of the UPR. This observation confirms and extends earlier findings (8) showing that PANDER, an islet-specific cytokine promoting apoptosis, inhibited p21 expression. Noteworthy, in this study (8), an inverse correlation between p21 and caspase 3 was identified that is in agreement with our present findings showing that in the absence of p21 caspase 3 
a

wt

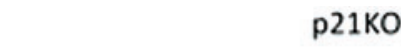

p21KO

CHOPKO
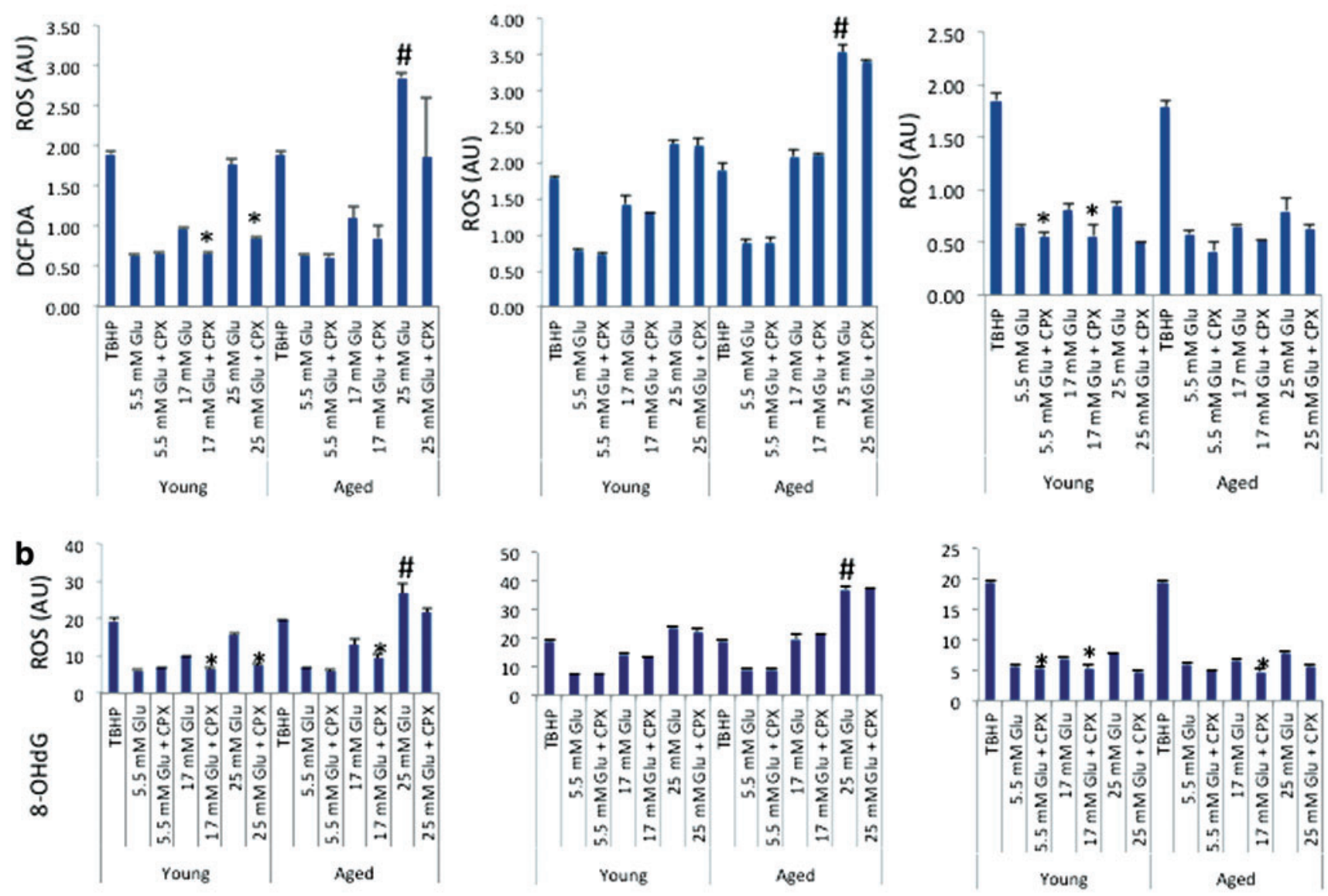

FIG. 10. Oxidative stress by p21 and CHOP in the presence of CPX. Effect of CPX at $20 \mu M$ in ROS production (arbitrary units, AU) triggered by high $(25 \mathrm{mM})$ or moderate $(17 \mathrm{mM})$ glucose (Glu) or iron citrate (Fe) (in $5.5 \mathrm{mM}$ glucose). TBHP was used as positive control for ROS production. (a) shows results obtained by DCFDA, whereas (b) by 8-OHdG measurements. ${ }^{*} p<0.05$ versus no CPX treatment. $\# p<0.05$ versus same treatment at different age (Student's $t$-test). All values are expressed as average \pm SD. ROS, reactive oxygen species. To see this illustration in color, the reader is referred to the web version of this article at www.liebertpub.com/ars

activation is induced. The fact that p21 ablation was insufficient to abrogate the increased sensitivity of the aged islets to high glucose and tunicamycin (aged p21KO islets remained more sensitive than younger islets), despite that it is regulated by $\mathrm{CHOP}(23,24)$, suggests that $\mathrm{CHOP}$ attains these aging-associated effects by 21 -independent mechanisms. To that end, although CHOP's activity is instructive for ER stress-associated apoptosis, for p21 such activity is rather permissive. Therefore, ablation of p21 activity is insufficient to eliminate the role of aging in diabetes sensitivity. Consistent with this notion, the deletion of $\mathrm{CHOP}$ blunted the induction of ER stress markers in the islets from both younger and older animals whereas the deletion of p21 only minimized these responses. Noteworthy, in the absence of p21, CHOP levels increased during ER stress instead of decreasing as in the wt islets, also supporting the notion that $\mathrm{p} 21$ protects from ER stress-associated apoptosis. With regards to the baseline levels of ER stress markers, no considerable change was detected, suggesting that these genes, p21 and CHOP, operate as modifiers of the UPR.

In line with the islets' findings are also the results from the in vivo experiments showing that aging increases the sensi- tivity of mice to diet-induced diabetes. Not only increased sensitivity to ER stress, but also compromised insulin release may account for the predisposition of the elderly to diabetes, as indicated by the reduced insulin secretion of islets from aged mice. The fact that $\mathrm{p} 21$-deficient islets exhibit reduced insulin production implies a regulatory role for $\mathrm{p} 21$ in insulin production, which may contribute to their compromised function at advanced ages. In the in vivo experiment, additional mechanisms involving an acquisition of insulin resistance may also contribute to the onset of age-dependent diabetes.

At the mechanistic level, it appears that although baseline levels of p21 in islets do not show a considerable difference between the aged and the young group, inhibition of p21 expression by ER stress was more striking in the former, which explains the increased sensitivity of the aged islets to ER stress-associated death. Recently, Kulkarni and colleagues (13) explored p21 expression in islets from 3 month and 11 month mice; however, no considerable differences were found. However, this study was performed by immunostaining and neither in isolated islets nor in response to increased glucose and ER stress, as done here. Surprisingly, the baseline levels of CHOP were lower in the older islets, 

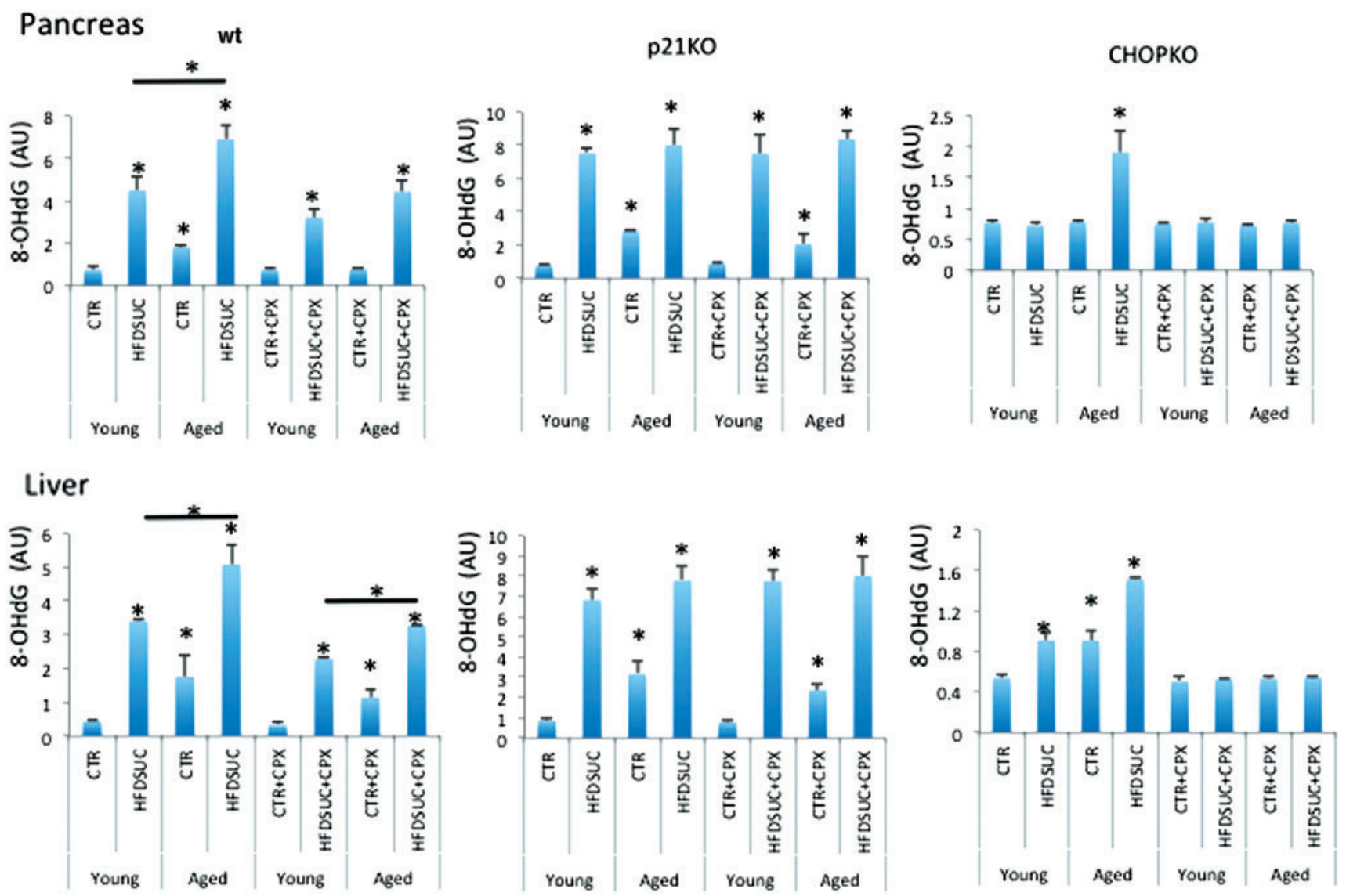

FIG. 11. Assessment of 8-OHdG in vivo. The levels of 8-OHdG (arbitrary units, AU) were determined in the liver and the pancreas of wt, p21KO, and CHOPKO 6 week-old and 14 month-old mice, respectively, treated with CPX, and received HFDSUC diet as described earlier, in Figure $6(n=3$ per experimental group). $* p<0.05$ (Student's $t$-test). All values are expressed as average $\pm \mathrm{SD}$. To see this illustration in color, the reader is referred to the web version of this article at www.liebertpub.com/ars

which, considering the inhibitory role of CHOP in p21 expression $(23,24)$ and the previously reported stimulation of ER stress-associated components during aging (30,41), was unexpected. However, relative $\mathrm{CHOP}$ induction and occupancy of p21 promoter were more pronounced in the aged islets, which underlines the significance of the inducibility rather than the absolute expression levels during the UPR. In addition, this experiment was performed in cultured islets in which activation of UPR may have been modulated as compared with the in vivo conditions.

In view of the protective role of p21 in islets' function and survival, we explored whether CPX, an activator of p21 expression, protects mice from diabetes. Indeed, mice that were pretreated with CPX were less sensitive to diet-induced diabetes than the animals receiving saline. This effect of CPX required intact $\mathrm{p} 21$ activity, because in $\mathrm{p} 21 \mathrm{KO}$ mice and islets the protective effects of CPX were compromised.

In vivo and especially in cultured islets, the protective effects of CPX were more prominent in the aged group in which CPX treatment protected better the islets from the older than the younger animals. Caspase activation was also inhibited by CPX more potently in the islets from the older mice, with the exception of caspase 2 that remained practically unaffected (or only modestly affected) by the tunicamycin or the high-glucose treatment in vitro. It is possible that CPX in- hibits caspase activation in a manner that does not involve or that operates downstream of caspase 2 . The complexity of the CPX mechanism of action, which likely is not limited to its iron-chelation activity, is also revealed by the observation that it exhibits opposite activity in CHOP and p21 regulation from DFO, another iron chelator (16). The latter dose dependently induces $\mathrm{CHOP}$ and suppresses p21, as opposed to CPX that stimulates p21 but inhibits CHOP at higher doses. This observation argues against the notion that the beneficial effects of CPX are due to its iron-chelation activity.

Why CHOP ablation also reduced the beneficial action of CPX remains unclear (Fig. 3). It could be due to the fact that CHOP ablation, by protecting from glucotoxicity and tunicamycin-associated toxicity, generates conditions at which the protective effects of CPX had been masked. The latter is supported by the fact that the prosurvival effects of CPX in wild-type islets are not detected under the culture of islets at normal conditions. Thus, CPX is effective, especially under conditions associated with stress, which are prevented by CHOP ablation. It has to be noted that formally it could be argued that both $\mathrm{p} 21$ and CHOP ablation surpass the beneficial effects of CPX, preventing the latter from producing antidiabetic activity in the absence of p21 or CHOP. However, the beneficial effects of CPX in vitro in islets' survival and the modest effects of p21 and CHOP ablation in the 
susceptibility of mice to diabetes argue against this notion. Formal proof, though, to this argument should be offered by utilizing additional mutant mouse models.

How CPX produces its protective activities remains elusive. A recent study performed in the context of brain hemorrhage and neuronal death showed that the protective effects of iron chelators were due to the inhibition of the proapoptotic ATF4-CHOP signaling (18), a notion that is also in line with our current observations showing that in the absence of CHOP, CPX is practically ineffective, both in vivo and in vitro. The observation that $\mathrm{DFO}$ produced opposite results from CPX in CHOP expression may be related to their different pharmacological properties and specificity to CHOP. Although the pro-survival activity of CPX is in line with its protective effects for islets, the fact that insulin release is inhibited contradicts its anti-diabetic action. An intriguing possibility is that CPX, by producing a moderate inhibition of insulin release, reduces ER stress in pancreatic islets, which, in turn, improves long-term survival and function. Indeed, the ER stress-alleviating results of insulin gene deletion in pancreatic islets has been demonstrated recently in mice bearing genetic ablation of insulin genes (44). In the present study, assessment of plasma insulin in animals receiving HFDSUC alone or after CPX administration indicated that fasting insulin levels were reduced in the animals that have received CPX. The observation that insulin levels followed the levels of plasma glucose implies that the pancreatic function was still maintained, a notion that is not surprising for this short-term and not-severe diabetes-inducing protocol. Thus, animals with higher levels of plasma glucose exhibited increased insulin values. This notion is supported by the observation that insulin sensitivity was elevated in the CPX-receiving mice. To that end, it is conceivable that increased insulin sensitivity compensates for the reduced

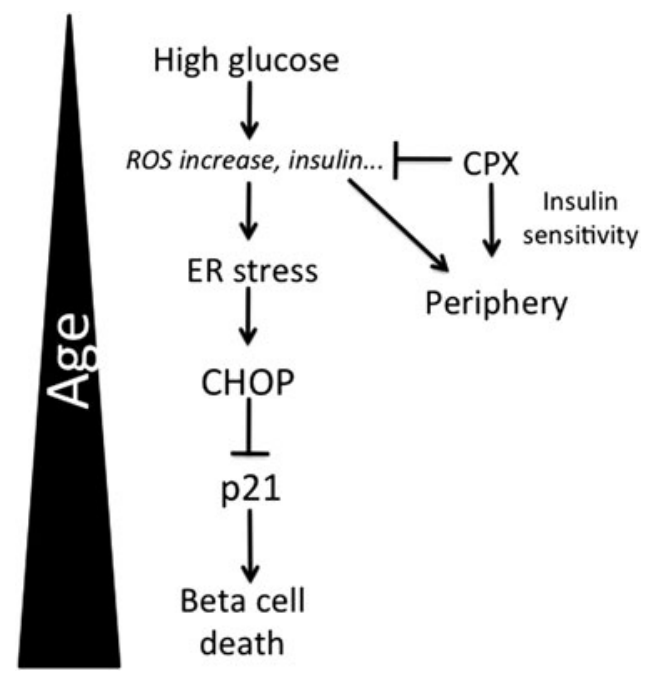

FIG. 12. The interplay of p21, CHOP, and CPX in pancreatic islets during aging. During aging, a progressive shift occurs in the UPR, via CHOP, from the pro-survival toward the proapoptotic mode. p21 produces antiapoptotic activity that is re-enforced by CPX that may act via not only p 21 to bypass the inhibitory effects of CHOP but also directly to CHOP according to mechanisms reported recently (15). Activity of CPX in the periphery, reducing insulin resistance, is also likely. insulin production, ultimately contributing to pancreatic health (Fig. 12). Furthermore, CPX was more effective in aged islets and mice in which the consequences of chronic perturbations of homeostasis in survival and functionality are more pronounced. The only exception was the surprisingly low insulin levels of insulin in the older CPX-receiving p21KO animals. In view of the fact that $\mathrm{p} 21$ deficiency is pro-diabetic and confers resistance to CPX treatment in vivo, a more severe pancreatic dysfunction may be suggested. Mechanistically, in line with this notion is the finding that iron stimulates insulin release in islets (9). By being an iron chelator, CPX inhibits this irondependent pathway for insulin secretion.

An additional mechanism that may also contribute to its inhibitory activity of insulin is the ability of CPX to directly scavenge oxygen radicals $(40,42)$. ROS are toxic and in various cellular systems, including glucotoxicity (45), have been shown to undergo a significant increase. In the present study, islets from aged animals produced higher amounts of ROS than islets from younger animals on culture at high glucose, which is in line with the reduced survival of older islets at glucotoxic conditions. The fact that CHOP ablation minimized ROS production on glucotoxicity and alleviated the effects of age strongly argues in favor of the pro-aging effects of CHOP in islets' physiology. Importantly, p21 ablation alleviated the protective effects of CPX, supporting the notion that CPX protection requires p21 activity. However, this effect was more apparent in younger than older islets, contrary to what we recorded in islets' survival and diabetes onset in vivo, which implies that alternative mechanisms may also account for the protection of islets' function and survival by CPX. These effects in ROS production recorded in islets cultured in vitro were in agreement with the levels of 8 OHdG recorded in vivo, in animals receiving HFDSUC alone or after CPX administration, which supports the biological relevance of cultured islet studies.

In the context of insulin regulation, ROS have been shown either directly or indirectly to stimulate insulin release in pancreatic islets $(38,40)$. Such ROS are readily produced by increased glucose concentrations (46), and, thus, their scavenging by CPX is anticipated to compromise insulin release. Consistent with these notions, anti-oxidants can reduce ER stress and improve protein secretion (22).

Collectively, in this study, we explored the role of aging in the sensitivity against diet-induced diabetes, a disease with increased prevalence in the elderly. By focusing on the survival and function of pancreatic islets, we showed that differential regulation of ER stress by mechanisms involving p21 and CHOP expression and activity contribute to ageassociated diabetes. Finally, we provided evidence that CPX, by mechanisms involving $\mathrm{p} 21$ activation and likely inhibition of CHOP activity, protects from diabetes in a manner that is particularly effective at more advanced ages (Fig. 12). Agedependent modulation of UPR emerges as a major modifier of the outcome of conditions such as diabetes that characterize the elderly.

\section{Materials and Methods}

\section{Chemical reagents}

CPX and DFO were purchased from Sigma-Aldrich. The chemicals mentioned earlier were dissolved either in medium or in dimethyl sulfoxide (DMSO) (Sigma-Aldrich). 


\section{Animals}

C57BL/6, CHOPKO, and $\mathrm{p} 21 \mathrm{KO}$ mice used in these studies were originally purchased from the Jackson Laboratory. All mice were housed and aged at the university of Athens in specific pathogen-free facilities in a temperaturecontrolled room $\left(20-22^{\circ} \mathrm{C}\right)$ with 12 -h light-dark cycles and maintained according to institutional guidelines of the Animal Facilities by the Athens University Medical School Ethics Committee in agreement with the European Union. The C57BL/6, CHOPKO, and $\mathrm{p} 21 \mathrm{KO}$ mice were divided into the following two groups of each genotype: group 1, 6 weekold mice; group 2, 14-month-old mice. All experiments were performed with female mice.

\section{Islet isolation and viability assessment}

Pancreatic islets were manually isolated from young (6 weeks) or aged (14 months) wild-type, p21-knockout (p21$\mathrm{KO}$ ), and CHOPknockout (CHOP-KO) mice, which were fed by regular diet, by the collagenase digestion technique (Sigma-Aldrich), as described in (19). Islet viability was determined indirectly by evaluating metabolic activity using the colorimetric (3-(4,5-dimethylthiazol-2-yl)-5-(3carboxymethoxyphenyl)-2-(4-sulfophenyl)-2H-tetrazolium) MTS by using the CellTiter 96 Nonradioactive Cell Proliferation Assay Kit (Promega), as described in (23). Each experiment was done in triplicate.

\section{Measurements of caspase activity}

About 100 islets of a similar size from young (6 weeks old) or aged (14 months old) wild-type, p21-deficiency, and CHOP-deficiency mice were subjected to caspase measurements by using the Caspase Colorimetric Protease Assay (KHZ1001; Invitrogen Corp.) according to the manufacturer's protocol, as described in (23). Each experiment was replicated with triplicate repeated measures. To determine the change in caspase activity, the absorbance of treated samples was compared with that of the untreated control group.

\section{Insulin secretion studies}

Islets were isolated from young and aged mice of each genotype and were seeded onto a 96-well plate at 20 islets per well in $100 \mu \mathrm{l}$ of RPMI 1640 medium (GIBCO, cat. no. 11879) containing $5.5 \mathrm{~m} M$ glucose. Islets were suspended in extracellular Krebs-Ringer (KR) solution (Sigma-Aldrich) for $30 \mathrm{~min}$ at $37^{\circ} \mathrm{C}$. Then, islets were further incubated with RPMI-1640 complete medium containing $25 \mathrm{mM}$ glucose alone or combined with CPX $(20 \mu M)$. After a $24 \mathrm{~h}$ incubation, the supernatants were assayed for insulin, which was measured by the Ultra Sensitive Mouse Insulin ELISA kit (Crystal Chem, Inc.) in accordance with the manufacturer's guidelines. Results were expressed as absolute insulin concentrations, as described in (23).

\section{In vivo experimental model}

Young and aged mice of each genotype (C57BL/6, $\mathrm{CHOPKO}$, and $\mathrm{p} 21 \mathrm{KO}$ mice) were randomly grouped and received three weekly oral gavages with CPX $(25 \mathrm{mg} / \mathrm{kg})$ prepared in a solution (4\% ethanol, $5.2 \%$ Tween 80 , and 5.2\%
PEG 400) or vehicle control for 1 month and fed with a control chow diet consisting of $10 \%$ of kcal as fat (low-fat diet) Open Source Diets D12450B and drinking water. After 1 month of CPX administration or vehicle control, young and aged mice of each genotype were fed with a high-fat diet, HFDSUC (HFD; Open Source Diets) D12451, with free access to (10\%) sweetened water (sucrose), as described (23). Blood glucose concentrations were measured after overnight fasting. Mice with a glucose concentration exceeding $180 \mathrm{mg} / \mathrm{dl}$ were considered diabetic, after 2 consecutive glucose measurements. Blood samples were taken from tail vein, and blood glucose concentrations were measured with a glucometer (Roche). In addition, blood samples $(1 \mathrm{ml})$ from young and aged mice of each genotype and group as previously described were collected in an EDTA bloodcollection tube and centrifuged at 1200-1500 $\mathrm{g}$ for $10 \mathrm{~min}$ at $4^{\circ} \mathrm{C}$. The supernatant (serum) was transferred into $1.5 \mathrm{ml}$ Eppendorf tubes and stored at $-80^{\circ} \mathrm{C}$ for insulin analysis. Serum insulin levels were determined by using the Ultra Sensitive Mouse Insulin ELISA Kit (CrystalChem, Inc.) in accordance with the manufacturer's guidelines.

\section{Measurement of cellular ROS production}

ROS measurements were measured by using the DCFDA Cellular ROS Detection Assay Kit (Abcam Plc.) in a 96well dark microplate in accordance with the manufacturer's guidelines. Samples were analyzed by using a Varioskan Flash micro-plate reader (Thermo-Scientific) with an excitation wavelength at $485 \mathrm{~nm}$ and an emission wavelength at $535 \mathrm{~nm}$. Tert-Butyl hydroperoxide was used as positive control.

\section{Mesaurement of 8-OHdG levels in tissues}

Mice were anesthetized by an intraperitoneal injection of pentobarbital $(80 \mathrm{mg} / \mathrm{kg})$ before the performance of surgical procedures. Pancreata and livers were rapidly excised. Then, the tissues were frozen in liquid nitrogen and kept at $-80^{\circ} \mathrm{C}$ until they were analyzed. 8-OHdG was measured with the highly sensitive 8-OHdG check ELISA kit (Genox Corp.) in accordance with the manufacturer's guidelines, as described in (17).

\section{Western immunoblotting}

Immunoblots were performed as described (22) by using the following antibodies: GADD153 (F-168), sc575 from Santa Cruz Biotechnology (1:50); p21 (F-5), sc-6246 from Santa Cruz Biotechnology (1:200); actin, clone C4 MAB1501 from Millipore (1:5000); BiP antibody (cat. no. 3183) from Cell Signaling (1:1000); GRP94 antibody (H-212), sc-11402 from Santa Cruz Biotechnology (1:500); horseradish peroxidase-conjugated anti-mouse (1:10,000), goat anti-rabbit IgG (1:10,000; Santa Cruz biotechnology, Inc.) for $1 \mathrm{~h}$. Densitometry values were estimated by the Image $\mathbf{J}$ software (National Institutes of Health). All blots were repeated at least three times, and similar results were obtained.

\section{$R T-P C R$ analysis}

After isolation, islets were placed in Trizol (Invitrogen) for RNA isolation according to the manufacturer's instructions. 
cDNA was synthesized by using iScript (Biorad, Life Science Research) by using the manufacturer's protocol. cDNA was then subjected to semi-quantitative PCR by standard methods. The oligonucleotide primers used for PCR were as follows:

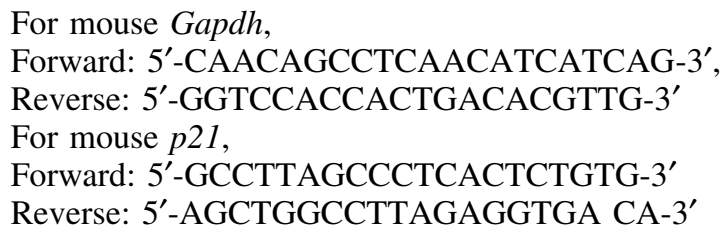

For mouse Gapdh,

Forward: 5'-CAACAGCCTCAACATCATCAG-3', Reverse: 5'-GGTCCACCACTGACACGTTG-3' For mouse $p 21$,

Forward: 5'-GCCTTAGCCCTCACTCTGTG-3' Reverse: 5'-AGCTGGCCTTAGAGGTGA CA-3'

\section{ChIP analysis}

ChIP studies were performed as described in $(23,24)$.

The PCR primer set used for the ChIP assay was as follows:

chop forward $15^{\prime}$ - GTGACGAGGGTCAGGCTATG -3' chop reverse $13^{\prime}$ - ATAGACTCGCCGAAGCTTGT $5^{\prime}(256 \mathrm{bp})$

\section{Statistics}

The results are expressed as the mean \pm SEM of at least three independent experiments. Comparisons between HFDSUC-treated animals and normal controls were performed with Student's $t$ test. $p$ values $<0.05$ were considered significant and are indicated in the text.

\section{Acknowledgment}

This study was supported by grant RAG051976A from NIH/NIA.

\section{Author Disclosure Statement}

No competing financial interests exist.

\section{References}

1. Ahima RS. Connecting obesity, aging and diabetes. Nat Med 15: 996-997, 2009.

2. Back SH and Kaufman RJ. Endoplasmic reticulum stress and type 2 diabetes. Ann Rev Biochem 81: 767-793, 2012.

3. Baker DJ, Weaver RL, and van Deursen JM. p21 both attenuates and drives senescence and aging in BubR1 progeroid mice. Cell Rep 3: 1164-1174, 2013.

4. Bensellam M, Van Lommel L, Overbergh L, Schuit FC, and Jonas JC. Cluster analysis of rat pancreatic islet gene mRNA levels after culture in low-, intermediate- and highglucose concentrations. Diabetologia 52: 463-476, 2009.

5. Ben-Zvi A, Miller E a, and Morimoto RI. Collapse of proteostasis represents an early molecular event in Caenorhabditis elegans aging. Proc Natl Acad Sci U S A 106: 14914-14919, 2009.

6. Brown JE. The ageing pancreas. Br J Diabetes Vasc Dis 141-145, 2012.

7. Brown MK and Naidoo N. The endoplasmic reticulum stress response in aging and age-related diseases. Front Physiol 3: 263, 2012.

8. Burkhardt BR, Greene SR, White P, Wong RK, Brestelli JE, Yang J, Robert CE, Brusko TM, Wasserfall CH, Wu J, Atkinson MA, Gao Z, Kaestner KH, and Wolf BA.
PANDER-induced cell-death genetic networks in islets reveal central role for caspase- 3 and cyclin-dependent kinase inhibitor 1A (p21). Gene 369: 134-141, 2006.

9. Erion KA T. Ferrante B. and Corkey J. Deeney. Iron stimulates insulin secretion in clonal pancreatic $\beta$-cells and dissociated rat islets. FASEB J 27: 1010.13, 2013.

10. Fu XL and Gao DS. Endoplasmic reticulum proteins quality control and the unfolded protein response: the regulative mechanism of organisms against stress injuries. BioFactors 40, 569-585, 2014.

11. Guerrero-Hernández A, Leon-Aparicio D, Chavez-Reyes J, and Olivares-Reyes JA, DeJesus S. Endoplasmic reticulum stress in insulin resistance and diabetes. Cell Calcium 56: 311-322, 2014.

12. Hasnain SZ, Prins JB, and McGuckin MA. Oxidative and endoplasmic reticulum stress in $\beta$-cell dysfunction in diabetes. J Mol Endocrinol 56:R33-54, 2016.

13. Hinault C, Hu J, Maier BF, Mirmira RG, and Kulkarni RN. Differential expression of cell cycle proteins during ageing of pancreatic islet cells. Diabetes Obes Metab 10 Suppl 4: 136-146, 2008.

14. Hitomi J, Katayama T, Taniguchi M, Honda A, Imaizumi $\mathrm{K}$, and Tohyama MN. Apoptosis induced by endoplasmic reticulum stress depends on activation of caspase-3 via caspase-12. Neurosci Lett 357: 127-130, 2004.

15. Islam MS and Loots du T. Experimental rodent models of type 2 diabetes: a review. Methods Find Exp Clin Pharmacol 31: 249-261, 2009.

16. Jung IR, Choi SE, Jung JG, Lee SA, Han SJ, Kim HJ, Kim DJ, Lee KW, and Kang Y. Involvement of iron depletion in palmitate-induced lipotoxicity of beta cells. Mol Cell Endocrinol 407: 74-84, 2015.

17. Kakimoto M, Inoguchi T, Sonta T,Yu, Imamura M, T. Etoh, et al. Accumulation of 8-hydroxy-2? -deoxyguanosine and mitochondrial DNA deletion in kidney of diabetic rats. Diabetes 51: 1588-1595.

18. Karuppagounder SS, Alim I, Khim SJ, Bourassa MW, Sleiman SF, John R, Thinnes CC, Yeh TL, Demetriades M, Neitemeier S, Cruz D, Gazaryan I, Killilea DW, Morgenstern L, Xi G, Keep RF, Schallert T, Tappero RV, Zhong J, Cho S, Maxfield FR, Holman TR, Culmsee C, Fong GH, Su Y, Ming GL, Song H, Cave JW, Schofield CJ, Colbourne F, Coppola G, and Ratan RR. Therapeutic targeting of oxygen-sensing prolyl hydroxylases abrogates ATF4dependent neuronal death and improves outcomes after brain hemorrhage in several rodent models. Sci Transl Med 8: 328ra29, 2016.

19. Li D-S, Yuan Y-H, Tu H-J, Liang Q-L, and Dai L-J. A protocol for islet isolation from mouse pancreas. Nat Protoc 4: 1649-1652, 2009.

20. Lublin A, Isoda F, Patel H, Yen K, Nguyen L, Hajje D, et al. FDA-approved drugs that protect mammalian neurons from glucose toxicity slow aging dependent on $\mathrm{Cbp}$ and protect against proteotoxicity. PLoS ONE 6:e27762, 2011.

21. Ma TC, Langley B, Ko B, Wei N, Gazaryan IG, Zareen N, et al. A screen for inducers of p21(waf1/cip1) identifies HIF prolyl hydroxylase inhibitors as neuroprotective agents with antitumor properties. Neurobiol Dis 49: 13-21, 2013.

22. Malhotra JD, Miao H, Zhang K, Wolfson A, Pennathur S, Pipe SW, et al. Antioxidants reduce endoplasmic reticulum stress and improve protein secretion. Proc Natl Acad Sci U S A 105: 18525-18530, 2008.

23. Mihailidou C, Chatzistamou I, Papavassiliou A, and Kiaris H. Regulation of p21 during diabetes-associated stress of 
the endoplasmic reticulum. Endocr Relat Cancer 22: 217 228, 2015.

24. Mihailidou C, Chatzistamou I, Papavassiliou AG, and Kiaris H. Improvement of chemotherapeutic drug efficacy by endoplasmic reticulum stress. Endocr Relat Cancer 22: 229-238, 2015.

25. Mihailidou C, Papavassiliou AG, and Kiaris H. A crosstalk between $\mathrm{p} 21$ and UPR-induced transcription factor C/EBP homologous protein (CHOP) linked to type 2 diabetes. Biochimie 99: 19-27, 2014.

26. Mihailidou C, Papazian I, Papavassiliou AG, and Kiaris H. CHOP-dependent regulation of p21/waf1 during ER stress. Cell Physiol Biochem 25: 761-766, 2010.

27. Mkrtchian S. Targeting unfolded protein response in cancer and diabetes. Endocr Relat Cancer 22:C1-C4, 2015.

28. Mlynarczyk C and Fåhraeus R. Endoplasmic reticulum stress sensitizes cells to DNA damage-induced apoptosis through p53-dependent suppression of p21(CDKN1A.). Nat Commun 5: 5067, 2014.

29. Mollereau B, Manié S, and Napoletano F. Getting the better of ER stress. J Cell Commun Signal 311-321, 2014.

30. Morimoto RI and Cuervo AM. Proteostasis and the aging proteome in health and disease. J Gerontol A Biol Sci Med Sci 69 Suppl 1:S33-S38, 2014.

31. Morley JE. Diabetes and aging: epidemiologic overview. Clin Geriatr Med 24: 395-405, 2008.

32. Naidoo N. ER and aging-Protein folding and the ER stress response. Ageing Res Rev 8: 150-159, 2009.

33. Oakes SA and Papa FR. The Role of Endoplasmic Reticulum Stress in Human Pathology. Ann Rev Pathol 10: 173-194, 2014.

34. Oslowski CM1 and Urano F. Measuring ER stress and the unfolded protein response using mammalian tissue culture system. Methods Enzymol 490: 71-92, 2011.

35. Oyadomari S, Koizumi A, Takeda K, Gotoh T, Akira S, Araki E, et al. Targeted disruption of the Chop gene delays endoplasmic reticulum stress-mediated diabetes. J Clin Invest 109: 525-532, 2002.

36. Papa FR. Endoplasmic reticulum stress, pancreatic $\beta$-cell degeneration, and diabetes. Cold Spring Harbor Perspect Med 2: 1-17, 2012.

37. Park CW and Chung JH. Age-dependent changes of p57 (Kip2) and p21(Cip1/Waf1) expression in skeletal muscle and lung of mice. Biochim Biophys Acta 1520: 163-168, 2001.

38. Pi J, Bai Y, Zhang Q, Wong V, Floering LM, Daniel K, et al. Reactive oxygen species as a signal in glucosestimulated insulin secretion. Diabetes 56: 1783-1791, 2007.

39. Puthalakath H, O'Reilly LA, Gunn P, Lee L, Kelly PN, Huntington ND, et al. ER Stress triggers apoptosis by activating BH3-only protein bim. Cell 129: 1337-1349, 2007.

40. Saadeh M, Ferrante TC, Kane A, Shirihai O, Corkey BE, and Deeney JT. Reactive oxygen species stimulate insulin secretion in rat pancreatic islets: studies using monooleoyl-glycerol. PloS One 7:e30200, 2012.
41. Salminen A and Kaarniranta K. ER stress and hormetic regulation of the aging process. Ageing Res Rev 9: 211217, 2010.

42. Sato E, Kohno M, Nakashima T, and Niwano Y. Ciclopirox olamine directly scavenges hydroxyl radical. Int J Dermatol 47: 15-18, 2008.

43. Senft D and Ronai ZA. UPR, autophagy, and mitochondria crosstalk underlies the ER stress response. Trends Biochem Sci 40: 141-148, 2015.

44. Szabat M, Page MM, Panzhinskiy E, Skovs $\varnothing$ S, Mojibian M, Fernandez-Tajes J, et al. Reduced insulin production relieves endoplasmic reticulum stress and induces $\beta$ cell proliferation. Cell Metab 23: 179-193, 2016.

45. Valavanidis A, Vlachogianni T, and Fiotakis C. 8-hydroxy2' -deoxyguanosine (8-OHdG): a critical biomarker of oxidative stress and carcinogenesis. J Environ Sci Health C Environ Carcinog Ecotoxicol Rev 27: 120-139, 2009.

46. Wang XZ, Lawson B, Brewer JW, Zinszner H, Sanjay a, Mi $\mathrm{LJ}$, et al. Signals from the stressed endoplasmic reticulum induce C/EBP-homologous protein (CHOP/GADD153). Mol Cell Biol 16: 4273-4280, 1996.

47. $\mathrm{Yu} \mathrm{T}$, Jhun $\mathrm{BS}$, and Yoon Y. High-glucose stimulation increases reactive oxygen species production through the calcium and mitogen-activated protein kinase-mediated activation of mitochondrial fission. Antioxid Redox Signal 14: 425-437, 2011.

48. Zinszner H, Kuroda M, Wang X, Batchvarova N, Lightfoot RT, Remotti $\mathrm{H}$, et al. CHOP is implicated in programmed cell death in response to impaired function of the endoplasmic reticulum. Genes Dev 12: 982-995, 1998.

Address correspondence to: Dr. Hippokratis Kiaris

Department of Drug Discovery and Biomedical Sciences University of South Carolina CLS 713, 715 Sumter Street Columbia, SC 29208-3402

E-mail: kiarish@sccp.sc.edu

Date of first submission to ARS Central, February 8, 2016; date of final revised submission, December 7, 2016; date of acceptance, December 7, 2016.

$\begin{aligned} & \text { Abbreviations Used } \\ \mathrm{ChIP} & =\text { chromatin immunoprecipitation } \\ \mathrm{CPX} & =\text { ciclopirox } \\ \mathrm{DFO} & =\text { deferoxamine } \\ \mathrm{ELISA} & =\text { enzyme-linked immunosorbent assay } \\ \mathrm{ER} & =\text { endoplasmic reticulum } \\ \mathrm{ROS} & =\text { reactive oxygen species } \\ \mathrm{TBHP} & =\text { tert-butyl hydroperoxide } \\ \mathrm{UPR} & =\text { unfolded protein response }\end{aligned}$

